PONTIFÍCIA UNIVERSIDADE CATÓLICA do RIO dE JANEIRO

\title{
Otimização de Processos Organizacionais Estudo de caso - Processo de Contas a Pagar (Puig Brasil)
}

\section{Gabriel Bittencourt Lemos}

Trabalho de Conclusão de Curso

CENTRO DE CIÊNCIAS SOCIAIS - CCS DEPARTAMENTO de AdMINISTRAÇÃo Graduação em Administração de Empresas 


\section{Gabriel Bittencourt Lemos}

\section{Otimização de Processos Organizacionais Estudo de caso - Processo de Contas a Pagar (Puig Brasil)}

Trabalho de Conclusão de Curso, apresentado ao programa de graduação em Administração da PUC-Rio como requisito parcial para a obtenção do titulo de graduação em Administração.

Orientador: Edmundo Eutrópio

Rio de Janeiro

Novembro de 2015. 


\section{Agradecimentos}

Agradeço a meu orientador deste trabalho, Edmundo Eutrópio, que muito me ajudou e sanou minhas dúvidas com profissionalismo e simpatia.

Também gostaria de agradecer a minha família e amigos, que ao longo da minha trajetória me ajudaram muito, e também aos entrevistados, que foram fundamentais para os resultados deste estudo. 


\section{Resumo}

Lemos, Gabriel Bittencourt, Souza, Edmundo Eutrópio C. de. Otimização de processos organizacionais, estudo de caso - processo de contas a pagar (Puig Brasil). Rio de Janeiro, 2015. 57 páginas. Trabalho de Conclusão de Curso - Departamento de Administração. Pontifícia Universidade Católica do Rio de Janeiro.

Este estudo visa analisar o processo de contas a pagar da empresa Puig Brasil e estabelecer seus atuais níveis de eficiência e eficácia, para então propor mudanças que venham a otimizá-lo. As teorias de autores renomados no domínio da administração que abordam temas relevantes em se tratando de gestão de processos organizacionais constituem o foco do estudo. A pesquisa foi realizada através de abordagem qualitativa, por meio de entrevistas em profundidade com pessoas que utilizam o processo regularmente, em diferentes níveis hierárquicos, para que se evidenciem todas as percepções do processo. Os grupos foram divididos em: operadores do processo, clientes internos e clientes externos (fornecedores). Identificaram-se, sobretudo, problemas em três etapas do processo. Na etapa de planejamento foram encontradas falhas na preparação dos funcionários para o uso da ferramenta que dá suporte ao processo. No que toca à implementação, destacam-se problemas no fluxo de informação dentro do processo. Na etapa de controle, ressalta a inexistência de indicadores para medir os resultados finais. Para solucionar e otimizar o processo foram propostas as seguintes mudanças: (1) elaboração e aplicação do treinamento dos novos funcionários diretamente pela área de contas a pagar, (2) desenho e compartilhamento do fluxo de informação para todos os envolvidos dentro do processo e (3) indicadores quantitativos e qualitativos para controle das mudanças propostas.

Palavras- chave

Eficiência, Eficácia, Otimização, Processo, Indicadores, Organização, Contas a pagar, Mapeamento, Controle. 


\section{Abstract}

Lemos, Gabriel Bittencourt; Souza, Edmundo Eutrópio C. de. Organizational processes optimization, Case Study - Process Accounts Payable (Puig Brasi). Rio de Janeiro, 2015. 57 pages. Trabalho de Conclusão de Curso - Departamento de Administração. Pontifícia Universidade Católica do Rio de Janeiro.

This study aims to analyze the Puig Brasil accounts payable process and establish its current levels of efficiency and effectiveness, and then propose changes to optimize it. The focus of the study was the theories of renowned authors in the field of management that address relevant issues when related to the management of organizational processes. The survey was conducted through a qualitative approach, through in-depth interviews with people using the process on a regular basis at different hierarchical levels, in order to show all the process perceptions. The groups were divided into: process operators, internal customers and external customers (suppliers). Particular problems were identified in three stages of the process. In the planning stage flaws have been found in the staff preparation for the use of the tool that supports the process. When it comes to implementation, we can highlight problems in the flow of information within the process. In control step, underscores the lack of indicators to measure final results. In order to optimize the process, the following changes were proposed: (1) development and implementation of the training for new employees directly in the area of accounts payable, (2) design and sharing of information flow for all involved in the process e (3) quantitative and qualitative indicators for control of proposed changes.

Key-words

Efficiency, Effectiveness, Optimization, Process Indicators, Organization, Accounts Payable, Mapping, Control. 


\section{Sumário}

1.Introdução 1

1.1. Objetivo do estudo 5

1.2. Relevancia do Estudo 5

1.3. Delimitações do Estudo 5

2 Revisão de literatura $\quad 7$

$\begin{array}{ll}\text { 2.1. Reengenharia } & 7\end{array}$

2.2. Organização Flexível 11

2.2.1. Meio Ambiente e seus elementos estratégicos 12

2.2.2. Interação permanente com o mercado e clientes 12

2.2.3. Estruturação das atividades por processosErro! Indicador não definido. 13

2.2.4. Subcontratação, parcerias e terceirização 13

$\begin{array}{ll}\text { 2.2.5. Forma de participação das pessoas } & 14\end{array}$

2.2.6. Aplicação dos recursos da tecnologia da informação 15

2.2.7. Gestão e avaliação econômica 16

2.2.8. Referenciais de Excelência 17

2.3. BPM ( Business Process Management) 17

$\begin{array}{ll}\text { 2.3.1. Mapeamento de processos } & 19\end{array}$

3. Métodos e procedimentos de coleta e de análise de dados do estudo 21

3.1. Etapa de coleta de dados 22

3.2. Fontes de informação selecionadas para coleta de dados no estudo 23

3.3. Procedimentos e instrumentos de coleta de dados utilizados no estudo 24

3.4. Formas de tratamento e análise dos dados coletados para o estudo 25

3.5. Limitações do estudo 25

4 Resultados $\quad 27$

4.1. A empresa Puig Brasil 27

4.2. O processo de contas a pagar 28

4.3. Mapa do processo 30 
4.4. Análise das entrevistas 32

4.5. Proposta 34

5 Conclusões $\quad 38$

5.1. Sugestões e recomendações para novos estudos 39

6. Referências Bibliográficas $\quad 40$

$\begin{array}{ll}\text { Anexo } 1 & 41\end{array}$

$\begin{array}{ll}\text { Anexo } 2 & 44\end{array}$

$\begin{array}{ll}\text { Anexo } 3 & 48\end{array}$

\section{Lista de figuras}

Figura 1: Evolução da taxa de desemprego no Brasil (IBGE.2015) .................... 1

Figura 2: Diagrama de contexto do processo (Gabriel Lemos,2015) ................ 29

Figura 3: Mapa do processo de contas a pagar as is (Gabriel Lemos,2015) ..... 31

Figura 4: Mapa do processo de contas a pagar to be (Gabriel Lemos,2015).... 37 


\section{Introdução}

O Brasil vive um difícil momento econômico, agravado pelo cenário de investimento internacional, com o rebaixamento da nota de crédito realizada pela Austing Rating. Os chamados países investidores percebem o país como de alto risco para investimentos em quaisquer dos setores da economia. As empresas instaladas no mercado brasileiro são afetadas, seja nos custos, seja no dia a dia das suas operações. Com a alta do dólar no país, que ultrapassou a casa dos $\mathrm{R} \$ 4,00$, as importações e operações cambiais ficaram mais difíceis, especialmente das multinacionais, necessitando assim de estruturas mais enxutas e processos com um nível de assertividade elevado para passar por essa fase "turbulenta" que o país atravessa.

Segundo IBGE (2015), "O desemprego no país continuou em alta e, no oitavo mês do ano, atingiu 7,6\% depois de bater 7,5\% em julho". Esse índice é o maior desde setembro de 2009 , quando estava na casa de $8,1 \%$. Abaixo segue um gráfico com a evolução dos índices de desemprego ao longo dos anos.

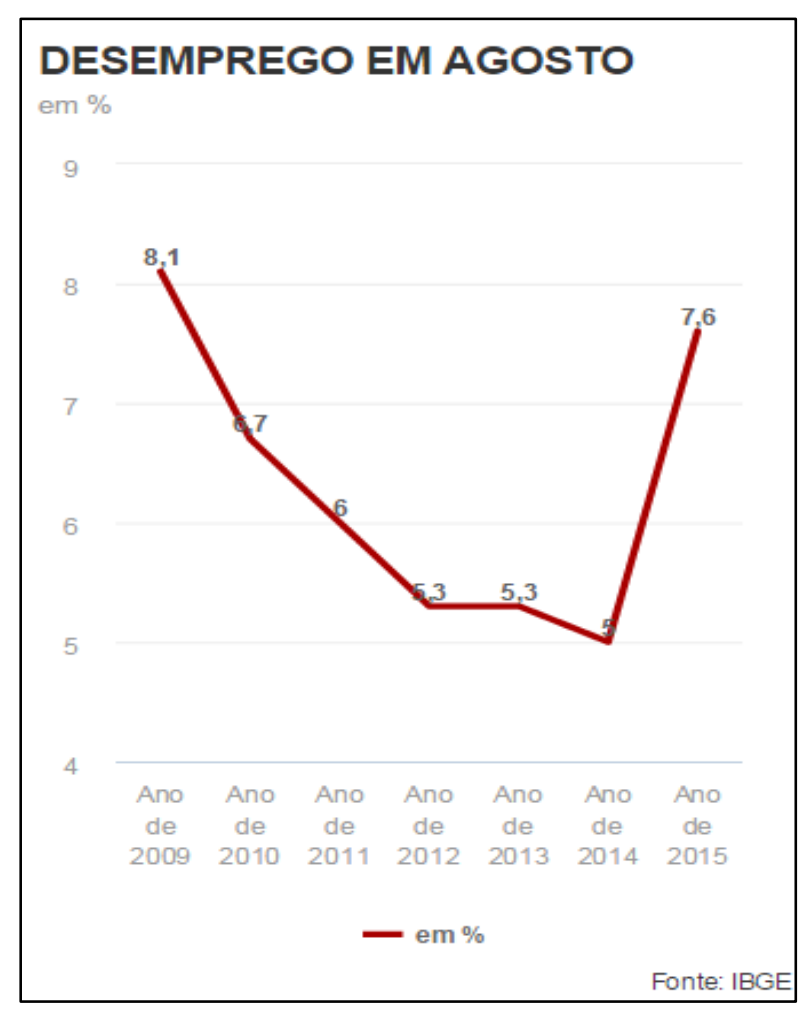

Figura 1: Evolução da Taxa de Desemprego no Brasil (IBGE, 2015)

Porém, o mercado de perfumaria e cosméticos não registrou, até o momento, essa crise vivida dentro do país. O Brasil neste segmento é líder global, ultrapassando importantes economias mundiais, como EUA e França, por 
exemplo. Segundo dados levantados pela Associação Brasileira da Indústria de Higiene Pessoal, Perfumaria e Cosméticos, 2015 (ABIHPEC) :

- As compras dentro do setor vão crescer $5 \%$, em 2015.

- Em valores, o salto será em torno de R\$22,7 bilhões em 2015.

- O investimento anual das empresas do setor saltou de $R \$ 9,3$ bilhões para $\mathrm{R} \$ 20$ bilhões.

Os números com certeza mostram que as oportunidades dentro do setor vão aumentar, mas em contrapartida a concorrência certamente ficará mais acirrada. Com o elevado nível na competitividade do mercado, quem tiver melhor modelo de negócio com certeza garante vantagem competitiva muito importante.

Segundo Pete Drucker (2002) "Todo trabalho importante realizado nas empresas faz parte de algum processo.". Nada produzido dentro de uma organização é produzido ou entregue sem que passe por um processo organizacional. Cada vez mais vemos que, com a globalização, os consumidores são bombardeados de informação de todos os lados. Com isso aumentou muito o acesso dos consumidores a diferentes tipos e marcas de produtos, o que permite compará-los e escolher o que melhor atende a suas demandas, quaisquer que elas sejam. Sendo assim, hoje em dia são raros os casos de organizações que se dão ao luxo de realizar suas funções sem se preocupar com desempenho dos seus processos.

Segundo Gonçalves (2000) "O futuro vai pertencer às empresas que conseguirem explorar o potencial da centralização das prioridades, as ações e os recursos nos seus processos". Dito isso, nas atuais condições do mercado, a eficiência nas operações é vital em todas as organizações de pequeno, médio e grande porte. Para entender as operações e o "core business" de cada empresa é indispensável estudar e entender os processos que acontecem diariamente no ambiente de trabalho. Trabalhar com processos implica destacar erros e acertos, pontos a melhorar e pontos a exaltar.

Com a globalização, os recursos vitais para todo negócio, capital e tempo, estão cada vez mais escassos.Também o acirramento da concorrência impõe aumento da cobrança de qualidade e controle do tempo de execução. Nesse contexto, as organizações não têm outra saída senão procurar oferecer produtos/serviços sempre mais baratos do que os da concorrência e ser flexíveis 
em face das constantes mudanças ambientais, visando assim agregar valor junto aos clientes e obter importantes vantagens competitivas em seu mercado.

Para tal, a otimização de processos é indispensável. Mais especificamente, é preciso mapear os processos, propor mudanças baseadas na análise prévia e controlar as mudanças realizadas. Os processos são formas de sintetizar as atividades de trabalho em organizações administrativas. Eles informam a direção, as ações e as rotinas por meio das quais o trabalho se deve organizar. Seus objetivos geram resultados definidos para facilitar a organização e agregar valores à instituição. Embora muitas vezes os processos sejam taxados, pejorativamente, de burocracia, eles são necessários para o andamento das instituições administrativas. Neste sentido, o estudo dos processos e de seu mapeamento torna-se fundamental na compreensão dos processos organizacionais e institucionais.

Ao analisar processos, é de extrema importância dedicar atenção especial para dois aspectos que definem diretamente a qualidade do processo em questão. Esses aspectos são eficiência e eficácia. Segundo Peter Drucker (2002), esses termos se definem da seguinte forma: "A eficiência consiste em fazer certo as coisas: geralmente está ligada ao nível operacional, como realizar operações com menos recursos - menos tempo, menos budget, menos pessoas, entre outros". "Já a eficácia consiste em fazer as coisas certas: geralmente relacionada ao nível gerencial/estratégico".

Trazendo esses termos mais especificamente para uma análise de processos, a eficiência de um processo é avaliada no que se refere a consistência do consumo de insumos e matérias primas para gerá-lo, em termos de qualidade, prazo, custo. Em outras palavras, a análise deve verificar se as entradas estão consistentes com as saídas. Já a análise de eficácia nos mostrará se o resultado gerado no final de cada processo estudado atende perfeitamente ou não às demandas a que está destinado. Esses dois aspectos vão direcionar a otimização do processo, tanto do ponto de vista interno quanto do ponto de vista externo.

Quando citamos uma visão organizacional voltada para processos, não podemos deixar de falar sobre a gestão de empresas por processos também conhecida com BPM (Business Process Management). A gestão por processos 
segundo o Guia BPM CBOK (2009) é definida da seguinte maneira : "Gestão de Processos de negócio ou BPM - Business Process Management é uma abordagem disciplinada para identificar, desenhar (ou projetar), executar, medir, monitorar e controlar processos de negócio, automatizados ou não, para alcançar consistência e resultados alinhados aos objetivos estratégicos da organização, envolvendo, ainda, com ajuda de tecnologia, formas de agregar valor, melhorias, inovações e o gerenciamento dos processos de ponta a ponta, levando a uma melhoria do desempenho organizacional e dos resultados de negócios".

Fazendo um breve resumo do BPM, ele consiste em alguns passos: 1) Traduzir a operação da organização em processos importantes e os que os suportam 2) Mapear os processos destacados acima detalhadamente 3) Definir indicadores de desempenho para acompanhamento 4) Identificar oportunidades de melhoria dentro da cadeia do processo 5) Implementar e controlar as mudanças necessárias para alcançar as oportunidades identificadas. Ao longo do estudo esse conceito de gestão por processos será melhor explorado e exemplificado, mas desde já com essa breve explicação, feita acima, vemos que para organizações do século XXI se diferenciarem das demais no mercado essa ferramenta de gestão é imprescindível.

Fala-se muito sobre o mapeamento de processos, que é uma atividade com o objetivo de desenhar, executar, documentar, monitorar e controlar a melhoria dos processos com vistas a alcançar resultados pretendidos numa organização institucional. Nesse sentido, o mapeamento de processos é uma iniciativa complexa e os resultados deste trabalho contribuem para auxiliar iniciativas semelhantes em outras instituições do mesmo segmento. Essa ferramenta é importantíssima para mensuração dos processos estudados. Mais à frente, neste trabalho, esse ponto será abordado com ênfase.

Dito isso, este estudo se propôs a aplicar a metodologia de padronização de processos no contas a pagar da filial brasileira da empresa PUIG, para responder à seguinte pergunta:

Que alterações devem sem feitas no processo de contas a pagar da empresa Puig Brasil, para que ele funcione com mais eficiência e eficácia? 


\subsection{Objetivo do estudo.}

O presente estudo tem como objetivo principal identificar oportunidades de melhoria no processo de contas a pagar da filial brasileira da empresa de perfumaria PUIG, que o tornem mais eficiente, eficaz e adaptado à realidade do nosso país.

\section{Objetivos Intermediários.}

- Caracterizar a filial brasileira da empresa de perfumaria PUIG no quadro da competição setorial.

- Definir como a eficiência e eficácia desse processo podem ser avaliadas;

- Medir o atual nível de eficiência e eficácia;

- Mapear e identificar oportunidades de melhora.

\subsection{Relevância do estudo}

Ao analisar o presente momento da economia e das empresas, percebemos que muitos problemas vividos estão ligados a dificuldades em processos, especialmente os financeiros. Examinando o processo de contas a pagar na PUIG Brasil nota-se que muitos dos problemas no dia a dia, são ligados pela ineficiência e ineficácia do mesmo.

Alguns dos problemas causados por essas falhas são: desgaste com alguns fornecedores por atrasos e ou problemas de pagamento, perda constante de tempo produtivo dos funcionários com retrabalho no processo, dificuldade nos controles de verba das diferentes áreas que usam diariamente o processo, falta de treinamento para o uso da interface.

Com este estudo, e mapeado todo o processo, acredita-se que seja possível minimizar e mitigar a maioria dos problemas citados acima.

\subsection{Delimitações do estudo}

As conclusões deste estudo são restritas ao processo de contas a pagar da empresa Puig Brasil, tendo sido utilizado o período de janeiro a dezembro de 2014 para a análise do processo. Não está incluída a análise dos processos 
internacionais de interface com a matriz e também os processos da matriz não estão sendo levados em consideração. Nenhuma das empresas concorrentes diretas no mercado brasileiro da empresa foi estudada ou analisada para a composição deste estudo.

Durante o estudo em questão foram analisadas diferentes teorias relacionadas a composição, desenhos e controles de processos organizacionais, com o objetivo de identificar oportunidades de melhoria no que se refere a insumos ou desenvolvimento dos processos - e assim otimizar o processo da Puig Brasil da maneira mais eficiente e eficaz possível.

Foram observados métricas e indicadores de avaliação de processos no mercado como um todo, e no setor de perfumaria e cosméticos em particular, bem como passos de planejamento e desenvolvimento de processos organizacionais, necessários ao mapeamento do processo observado.

Assim, após estudar e colher o máximo de informações sobre o assunto, foram apresentadas as reais eficiência e eficácia do processo de contas a pagar da Puig Brasil, no período estudado, para clientes internos e fornecedores, e identificadas alternativas de otimização, que podem ser adotadas pela organização. 


\section{Revisão da Literatura}

Neste capitulo são apresentados os principais conceitos que foram explorados no trabalho, a partir da literatura sobre o problema estudado, para tornar o processo estudado mais eficiente e eficaz, agregando valor à organização dentro e fora dela.

Os conceitos abordados nesse capítulo são de extrema relevância quando são estudados processos organizacionais.

O primeiro a ser abordado é o da reengenharia de processos na visão de Michael Hammer (1997). Também são revistos ao longo desse capitulo conceitos sobre organização flexível como definidos por Tashizawa Takeshy (1996) e também sobre gestão por processo (BPM), tema abordado por Rogério Valle e Saulo Barbará de Oliveira (2013). Outros autores também ajudam na compreensão dos temas citados acima ao longo do trabalho.

\subsection{Reengenharia}

Um dos métodos mais difundidos e utilizados pelas empresas na busca por melhoria nos negócios é a reengenharia. A seguir veremos como ela aparece na visão de alguns autores.

Os processos variam quanto às demandas de produção, eficiência e flexibilidade. Quando essas condições não são atendidas, é possível afirmar que algo pode ser modificado para aprimorá-lo. Para isso pode ser necessária uma Reengenharia.

O início do século $X X$ foi marcado pela difusão de um novo método de gestão organizacional conhecida como "reengenharia", criada por Michael Hammer. A reengenharia, segundo Michael Hammer (1994), parte da premissa de que a disponibilidade da alta tecnologia de informação permite reorganizar os processos das organizações de uma nova maneira, capaz de extrair dessa tecnologia inúmeros benefícios para o funcionamento das organizações, o que não foi possível em etapas anteriores em que a tecnologia de informação ainda não havia atingido os níveis de sofisticação e disponibilidade atuais. Outro ponto relevante, abordado por Hammer, é o fato de que com a globalização o grau de exigência dos clientes aumentou muito, pois tornou-se possível negociar com empresas em outros países do mundo. Com isso, algumas empresas norte- 
americanas começaram a perder mercado, especialmente para o mercado oriental.

De uma forma mais genérica, a reengenharia se propõe a mudar a estrutura organizacional para entender a melhor forma de realizar um processo, levando em consideração esse novo nível de tecnologia da atualidade.

Em seu livro, Além da Reengenharia, Michael Hammer (1994) define a diferença entre tarefa e processo da seguinte forma: "A diferença entre a tarefa e processo é a diferença entre a parte e o todo. Uma tarefa é uma parte do trabalho, uma atividade normalmente realizada por uma única pessoa. Um processo, por outro lado, é um grupo de tarefas relacionadas que, juntas, geram um resultado que tem valor para o cliente.". Essa foi a grande virada de chave das empresas na virada do século XX. Sempre voltadas para as tarefas, as organizações não enxergavam que a saída era focar nos processos, pois eles sim sintetizavam o valor percebido pelos clientes.

A Reengenharia se estrutura sobre três pilares, denominados por Michael Hammer de habilitadores ou facilitadores. Eles são : recursos humanos, processos e a tecnologia da informação. Nesta parte, descrevo esses três pilares do redesenho de processos dentro de uma organização.

No que se refere a recursos humanos, Morris e Brandon (1993) afirmam que, com a implementação dessa visão de gestão organizacional, os funcionários acabam por trabalhar de modo diferente do que estavam habituados, recebendo novos conhecimentos, tarefas e atribuições. Isso gera um desconforto e uma apreensão por parte dos funcionários. O departamento de recursos humanos é essencial para poroporcionar a esses funcionarios uma direção e um sentimento de segurança e pertencimento para atravessar a fase de desconfiança. Hammer (1994) aponta para a reengenharia como uma nova organização das funções organizacionias e um novo metodo de controlá-las. Para ele, "Concentrando-se nos clientes e enfatizando a orientação para os processos, a reengenharia está eliminando o trabalho industrial tradicional e, com ele, o próprio conceito de trabalhador industrial. Surge, em seu lugar, o trabalho amplo, orientado para os processos, que precisa ser preenchido por um novo trabalhador". Para Hammer, essa nova função do trabalhador precisar ser apresentada e ensinada aos funcionarios impactados. 
Destacando o segundo pilar da reengenharia, podemos dizer que a sua ênfase está no redesenho dos processos já existentes na organização. Segundo Hammer, essas modificações são fruto da substituição do enfoque funcional centralizado, para o novo conceito voltado para os processos, onde a organização passa a ser orientada a entender e atender às necessidades e exigências do mercado e de seus clientes diretos, internos e externos. A reengenharia pretende proporcionar a composição de processos abrangentes, compostos somente por algumas tarefas bem determinadas e interdependentes. Para o redesenho dos processos atuais das organizações, alguns pontos tem que ser entendidos internamente, Segundo Hammer (1994), primeiramente uma análise de grau de importancia dos porcessos tem que ser realizada, pontuando os mais e menos importantes. Após isso, uma pesquisa sobre o grau de satisfação e eficiência e eficácia também terá que ser efetuada, após o que podemos começar a mapear o processo e buscar alternativas para mudá-lo para a visão voltada para a gestão por processos.

Finalmente chegamos ao último e não menos importante terceiro pilar da reengenharia, a tecnologia da informação. $\mathrm{Na}$ atualidade, as organizações necessitam de respostas rápidas e eficientes para as mudanças no mercado, sejam dos clientes ou de seus concorrentes. Para obter essas respostas a tecnologia da informação é uma ferramenta essencial, com a entrada da internet nos processos das empresas essa ferramenta ficou ainda mais imprescindível.

Segundo Gonçalves (1995), nas novas empresas a tecnologia da informação passa a ser um apoio aos objetivos estratégicos, e ela terá que ser usada para tal. Em sua nova fase, TI será :

- Ferramenta de renovação constante nos processos organizacionias : TI é a principal ferramenta de adequação dos processos organizionais e na busca dos objetivos estratégicos.

- Agente direto de relacionamento com clientes : TI está diretamente ligada ao relacionamento que a empresa tem com seus clientes, essa é uma das atribuições mais estratégicas para a ferramenta.

- Elemento de Adequação entre o mercado e a organização : O ambiente vive em constante mudança, e as organizações não conseguem se adaptar com a rapidez que o mercado exige. O TI ajuda a perceber, absorver e implementar essa mudanças 
internamente e ajudar as pessoas das organizações nessa adaptação.

Para Morris e Brandon (1993) "o recente impulso dos esforços de reengenharia deve-se quase que inteiramente ao reconhecimento de uma maior necessidade de competir para que uma empresa tenha sucesso ou até mesmo sobreviva. A economia de mercado é a força que mais frequentemente motiva a reengenharia". Segundo esses autores, as metodologias das empresas devem estar sempre alinhadas com as expectativas do mercado, isso já é uma realidade para muitas empresas no mercado. Mas existem casos em que ainda não estão orientadas dessa forma; para elas Morris e Brandon (1993) descrevem quatro passos para implementação de uma reengenharia:

1a Passo: Preparação: consiste em listar os processos da empresa, selecionar um ou mais processos a redefinir e mobilizar recursos para o projeto;

$2^{\mathrm{a}}$ Passo: Planejamento: devem-se garantir os meios (tempo, pessoas e orçamento (recursos), estruturar as equipes de trabalho e distribuir tarefas;

$3^{\text {a }}$ Passo: Implementação: analisar os processos selecionados (responsável, envolvidos, pontos fracos e pontos fortes), reinventar os processos (visão cliente/resultado esperado), avaliar o impacto da mudança e implementar esses processos.

$4^{\text {a }}$ Passo: Avaliação: medir e comunicar os resultados, controlar o processo e gerir o impacto das alterações nos outros processos.

O redesenho dos processos na verdade implica na mudança de posicionamento das pessoas ao lidar com as etapas da mudança. Esta exigência de mudança de posicionamento das pessoas está intimamente ligada à questão de adaptação às mudanças.

De acordo com o tema proposto no presente estudo a reengenharia se vê necessária, pois com as mudanças propostas no ultimo capitulo alguns pontos vão ser modificados drasticamente internamente dentro da organização. Para que as mudanças sejam bem aceitas e melhorem os resultados da empresa este tema é de extrema relevância. 


\subsection{Organização Flexível}

$\mathrm{Na}$ atualidade, é indiscutível a importância das organizações se adaptarem às mudanças ambientais; em consequência, é preciso prever e propor ações para minimizar seus prováveis impactos na empresa.

O conceito de organização flexível implica em uma estrutura organizacional capaz de identificar e classificar os processos organizacionais dentro da empresa. Identificar os processos produtivos e os de apoio e classificá-los segundo a relevância estratégica deles para a organização. (TACHIZAWA E SCAICO,1996)

Essa segregação é realizada de acordo com cada modelo de negócio e setor em que a empresa esta inserida. Segundo Tachizawa e Scaico (1996), "Esta definição leva em conta o ramo de negócios da organização, de forma a subsidiar a delimitação dos processos produtivos e estratégicos." Uma vez conhecida a relevância de cada processo torna-se possível a traçar uma estratégia para terceirizar atividades que não agregam valor aos processos estratégicos da empresa, e também os processos considerados de apoio.

Tachizawa e Scaico (1996) descrevem da seguinte maneira a sequência de ações necessárias à adequação das organizações ao conceito de organização flexível :

- Meio Ambiente e seus elementos estratégicos;

- Interação permanente com o mercado e clientes;

- Estruturação das atividades por processos;

- Subcontratação, parcerias e terceirização;

- Forma de utilização das pessoas;

- Aplicação dos recursos da tecnologia da informações;

- Gestão e avaliação econômica,

- Referenciais de excelência

A seguir analiso brevemente cada uma, para melhor entendimento do conceito de organização flexível. 


\subsubsection{Meio Ambiente e seus elementos estratégicos}

Conforme Tachizawa e Scaico (1996), “...mercadologicamente, parte-se de fora para dentro segundo um enfoque sistêmico. É no contexto externo à empresa que ocorrem as mutações ambientais que ditam a interrupção ou continuidade, desde que seja adaptável e flexível, da vida das organizações". Para que possa responder adequadamente às mutações ambientais a organização necessita de uma estrutura interna enxuta, para que assim seja ágil para as constantes mudanças ambientais, as quais não podem ser controladas pela empresa. Uma análise ambiental minuciosa tem que ser realizada para o entendimento de agentes externos que interagem diretamente com a empresa estudada. Esses agentes são específicos dependendo da estrutura de negócio da organização estudada e do setor que ela está inserida, mas de um modo geral exemplos desses agentes são: clientes, fornecedores, bancos, governo entre outros. Para os autores Tachizawa e Scaico (1996): "A organização esperada no contexto de um cenário realista face às mudanças que estão ocorrendo no mercado é a descrita a seguir, que se pode chamar de modelo de organização flexível". Como pressupostos deste modelo, tem - se:

- Concentrar os esforços nas atividades estritamente vinculadas à missão da organização;

- Repassar para terceiros, em regime de subcontratação, as atividades que não agregam valor diretamente aos serviços prestados pela organização.

- Organização das atividades e tarefas em torno a processos, de forma a racionalizar o fluxo de decisões e informações nos planos intra (entre processos) e interorganizacional (junto a fornecedores, clientes e entidades externas)".

\subsubsection{Interação permanente com o mercado e clientes}

Mercado e clientes são partes expressivas do que entendemos por ambiente das organizações. Conhecer as necessidades dos clientes, as características da concorrência, o perfil dos fornecedores, as linhas de crédito disponíveis - tudo isso somente será possível se a interação com esses agentes é constante e profunda. Para tal destaca-se a relevância do processo de 
atendimento, através do qual as necessidades de clientes, as características de fornecedores, as oportunidades de crédito, penetram o tecido da organização e, frequentemente, contribuirão para retroalimentar as decisões de marketing e de produção.

Outra característica essencial da organização flexível é a obtenção e o tratamento de informações relevantes sobre as características da concorrência. Produtos, preços, política comercial, capacidade de produção, estrutura comercial - tudo que permita qualificar a tomada de decisões na organização deve ser capturado, classificado e absorvido pela organização flexível, conforme nos ensinam Tachizawa e Scaico (1996), sempre com o objetivo de conquistar a excelência nos processos, medida através de indicadores de qualidade e de desempenho que permitam estabelecer desafios e medir resultados com objetividade.

\subsubsection{Estruturação das atividades por processos}

Abordando agora a estruturação das atividades por processos, o modelo nos mostra que a organização flexível exige uma estrutura interna ágil para reagir imediatamente em face de mutação ambiental relevante. Para dotar a estrutura da agilidade necessária para tais reações se faz necessário analisar o que realmente é necessário para a empresa, segundo Tachizawa e Scaico (1996) "A maneira proposta para a identificação do que é essencial na organização e do que é acessório é a hierarquização dos processos sistêmicos, particularmente aqueles considerados produtivos".

Essa hierarquização pode ser feita individualmente para cada processo considerado chave para a organização ou simultaneamente ( no caso de existirem poucos processos chaves na empresa estudada). Esse modelo propõe a segregação em duas esferas: a esfera estratégica e a operacional, os processos serão separados desta maneira.

\subsubsection{Subcontratação, parcerias e terceirização}

Como já mencionado neste trabalho, tudo que for considerado como processo que não tem relação alguma com os objetivos estratégicos da empresa, deve ser analisado para ser terceirizado ou subcontratado por outra empresa, de forma a concentrar os esforços internos nos processos que se 
alinham e auxiliam no cumprimento dos objetivos estratégicos da organização. Dito isso, para Tachizawa e Scaico (1996), "Como subcontratações, parcerias e terceirização, subentende-se, basicamente, aproveitar as possibilidades e a capacidade da organização de estabelecer parcerias, tanto para frente, junto a clientes, como para trás, junto a fornecedores. Tais parcerias são uma forma alternativa à possibilidade de integração vertical da organização, onde a mesma tem completo domínio das fontes de suprimento de insumos produtivos ou de canais de comercialização junto aos consumidores finais/clientes.". Para os autores, a empresa precisa encontrar clientes e fornecedores que tenham experiência e "network" dentro do mercado que as ajudem em seus processos de apoio.

As parceiras fixadas precisam complementar o modelo de negócios da organização, visando sempre o melhor atendimento aos clientes. O nível de possibilidade de integração com esses parceiros varia de acordo com o tipo de negócio no qual a empresa está inserida. Com isso os fornecedores e clientes viram parceiros da organização, o que é uma ótima relação entre elas visto que elas dependem uma da outra. Fica clara a maior vantagem para a empresa do modelo proposto, que é: todo o esforço interno fica voltado no que a organização flexível faz de melhor e subcontratando empresas especializadas para realizar o restante, que elas fazem melhor do que ela própria. Alguns exemplos de processos que podem ser realizados através de parcerias, de uma maneira genérica (lembrando que isso varia entre empresa e setores), são: mão de obra, treinamento, desenvolvimento de recursos humanos, pesquisas de mercado e serviços administrativos. Tachizawa e Scaico (1996).

\subsubsection{Forma de participação das pessoas}

O modelo de organização flexível assume que nos processos as pessoas são importante ferramenta para resultados satisfatórios e adota nova abordagem para o assunto. Segundo Tachizawa e Scaico (1996), “A organização flexível propõe tratamento diferenciado para as diferentes categorias de pessoas a serem utilizadas nos processos produtivos e de apoio."

As transformações pelas quais vem passando o mercado global, em especial sob o ponto de vista do aumento exponencial da competição entre as empresas, provocam forte instabilidade na demanda de mão de obra, afetada diretamente pelos vales e picos dos negócios e pelas sazonalidades. A reestruturação das empresas, necessária para a busca do sucesso no novo ambiente, também é um vetor que conduz à liberação de parte da mão de obra. As empresas passam a repensar suas estruturas 
nesse novo ambiente, em que se produz um excedente de mão de obra, tanto na esfera das atividades complexas quanto na faixa das tarefas rotineiras. É nesse contexto que nascem os novos modelos de organizações flexíveis, que darão origem a novos tipos de relacionamento entre as empresas e seus colaboradores, sempre em busca de melhores resultados.

O grupo de trabalhadores que compõe o modelo de organização flexível será então segmentado. Os empregados de cargos centrais, vinculados diretamente à empresa, tornam-se menos numerosos, ainda que considerados de extrema importância para o futuro da organização. Segundo Tachizawa e Scaico (1996), esse grupo irá obter significativas vantagens: “... Maior segurança no emprego, boas perspectivas de promoção e reciclagem, importantes benefícios". Algumas características adicionadas serão requeridas nesse grupo: flexibilidade, adaptabilidade e mobilidade. É indicado para trabalhadores que ocuparem esses cargos centrais um rodízio em suas funções, de tempos em tempos, buscando sempre agregar valor a cada área, gerando valor para organização como um todo. Dependendo dos picos de demanda do mercado, subcontratações e terceirizações são indicadas para as empresas flexíveis, mesmo em funções de alto nível. Não se pode perder o referencial de excelência.

As operações restantes são separadas em dois grupos periféricos. O primeiro é composto de trabalhadores de tempo integral com habilidades que são facilmente encontradas no mercado. Este trabalho é definido como manual e repetitivo, e por isso a rotatividade é alta e não há uma perspectiva de crescimento desses funcionários (Lembrando que isso depende do modelo de negócio da organização estudada). Exemplo: Área financeira. O outro grupo é constituído pelas subcontratações, contratos flexíveis, terceiros, consultores e pessoas com contratos por tempo determinado, ou seja, são pessoas que se incorporam à empresa conforme as demandas sazonais do mercado; é um grupo que tem menos segurança que o anterior.

\subsubsection{Aplicação dos recursos da tecnologia da informação}

O uso de ferramentas de tecnologia da informação dentro da organização flexível gera benefícios em vários âmbitos, tanto internamente quanto externamente. Segundo Tachizawa e Scaico (1996) "No plano interno tem-se a ampliação da capacidade de processar informações, além daquela proporcionada pela própria conformação da estrutura organizacional e, portanto, de ampliar o processo decisório, possibilitando com isso a obtenção de estruturas mais achatadas e com menor numero de níveis hierárquicos." Essa estrutura mais achatada como citam os autores, possibilita que a organização se 
ajuste com mais facilidade às mutações aceleradas do mercado. Como exemplos de recursos adotados para organizações flexíveis, tem - se : a utilização de redes locais voltadas para a ativação de comunicação, além de sistemas integrados de fácil uso. Essas ferramentas auxiliam no fluxo correto de informações interno, promovendo assim uma eficiente gestão de interfaces entre os processos.

Para a organização flexível o contato com entidades externas é fundamental, e para esse relacionamento constante ferramentas de tecnologia da informação são primordiais. Segundo Tachizawa e Scaico (1996) " Com os recursos das tecnologias da informação, a organização flexível tem a possibilidade de interagir eletronicamente com seus fornecedores, com seus distribuidores e consumidores e, complementarmente, com entidades parceiras em alianças estratégicas." Algumas sugestões de tecnologias indicadas para a organização flexível, como recursos do comércio eletrônico, como e-business, $B 2 B, B 2 C$, entre outras.

Com o uso desses recursos tecnológicos torna-se possivel a comunicação dentro e fora da organização de forma eletrônica, viabilizando a conectividade completa do fluxo de informações e de documentos, ou seja, criando alianças estratégicas entre empresas que estariam sempre ligadas.

\subsubsection{Gestão e avaliação econômica}

$\mathrm{Na}$ atual conjuntura do mercado global de alta competitividade, as organizações são obrigadas a trabalhar com um alto grau de produtividade para sobreviver. Para isso a utilização da visão de unidade estratégica de negócios existente na estrutura da empresa é de extrema importância, pois será com ela que se torna possível mensurar a real contribuição das diversas unidades operacionais e não operacionais para o objetivo final da empresa.

Segundo Tachizawa e Scaico (1996), "Deve ser levada em conta, ainda, a visão de clientes e serviços, em que para cada conjunto de clientes/serviços devem ser atribuídas receitas externas e internas geradas, com os correspondentes custos/despesas incorridos, para fins de apuração de contribuição marginal especifica." Ou seja, para essa visão produtiva, aspectos internos e externos para mensuração da realidade de cada organização. Desta 
forma se torna possível o destaque de processos ou conjunto de processos que devem ser tratados de forma diferenciada, Segundo Tachizawa e Scaico (1996) "Neste contexto, um processo ou conjunto de processos são configurados como se fossem uma empresa à parte, com real responsabilidade de lucro ou prejuizos.".

\subsubsection{Referenciais de excelência}

A organização flexível deve comparar-se todo o tempo com os lideres de mercado, que constituem referenciais de excelência. Estes referenciais devem ser buscados através de benchmarking. Segundo Tachizawa e Scaico (1996), "O termo benchmarking expressa um conceito cada vez mais utilizado em trabalhos técnicos e estudos gerenciais, qual seja, a noção de referenciais de excelência, significando um conjunto de informações obtidas junto a organizações de desempenho considerado excelente, com base nas quais podese balizar a posição de uma organização qualquer em foco". Ou seja, deve-se buscar no mercado organizações, no setor em que a empresa está inserida, que apresentem notoriedade de boas práticas e conhecê-las tão bem quanto possível, de forma a extrair bons ensinamentos para a melhoria dos processos organizacionais..

Após a obtenção de tais referências, será necessário aplicá-las na organização e nos processos produtivos, principalmente nos que tem relação direta com o alinhamento da empresa com os padrões pesquisados externamente.

\subsection{BPM ( Business Process Management)}

O BPM ou Business Process Management, mais conhecido no Brasil como gestão por processos de negócios, é um termo novo dentro da administração de empresas. Ele surge no início do século XX, quando Michael Hammer, entre outros autores, começam a estudar os processos internos nas organizações.

Após isso, nos anos 2000, ele toma forma e vem para realidade do mercado. Foi aí que a chave das empresas virou, elas passaram a se preocupar 
com processos e deixaram de lado preocupações com funções e procedimentos, que antigamente eram o foco principal nas empresas de todo o mundo. Segundo Vale e De Oliveira (2009), "Por se tratar de atividade essencialmente humana, O BPM poderá ter diversas facetas aplicáveis com sucesso nas organizações. È difícil prever, simplesmente vendo um modelo esquematizado, se ele funcionará perfeitamente ou não. Isso porque as pessoas que o implantam ou o usam podem fazer toda a diferença." Ou seja, cada organização, dependendo de sua estrutura ou do setor em que ela esta inserida, terá uma forma particular de gestão por processos. Porém, existem aspectos comuns a todas elas e este capitulo será dedicado a identificar e explicar esses pontos comuns.

O processo de implementação do BPM tem diversas particularidades, mas existe um ciclo que é comum a todas organizações que o tentem implementar. Primeiramente, existe o Planejamento do BPM, que entre, outras coisas, compreende: a definição dos processos críticos (processos diretamente ligados a estratégia organizacional) dentro da organização, a priorização de atividades, formação de equipes, controle de atividades selecionadas, sempre levando em consideração o ambiente externo e o planejamento estratégico posto em prática. Após essa etapa de planejamento, já com diretrizes e especificações traçadas, modelar e otimizar processos será o novo passo. A primeira etapa será uma modelagem (mapeamento) dos processos críticos escolhidos tal como eles são no momento presente (As Is) e projetá-los como deveriam ser (To Be), para isso, é necessário analisar o processo, efetuar simulações para finalmente alcançar tão desejada melhoria do processo. Após a etapa de modelagem, existe uma fase crucial do BPM, que é a implementação dos novos processos. Essa etapa é complicada pois, por se tratar de mudança, sempre existe uma certa resistências de parte das pessoas envolvidas, e mudanças costumam gerar conflitos. Cabe ao gestor procurar internalizar nas suas equipes os objetivos estratégicos da organização, aproveitando ao máximo os benéficos das otimizações em seus processos.

Após todos os passos listados acima, chega o momento de controlar e analisar os processos. Para isso, algumas ferramentas ajudam e muito os gestores das empresas. São elas: estatísticas, controle de conjuntos de instâncias de processos e auditorias. Essas ferramentas ajudam muito, pois com elas é possível mensurar e controlar se os objetivos esperados estão sendo alcançados, além de prover dados para relatórios gerenciais regulatórios. 
Alem do que foi dito anteriormente o uso de indicadores é essencial para o controle dos processos chaves para a empresa. Segundo Valle e De Oliveira (2013), "O BPM engloba atividades relacionadas ao controle do geral do processo (por meio de diversos recursos, como indicadores, BAM, BI, BSC, métodos estatísticos e diagramas de causa e efeito), gerando informações que posteriormente realimentarão as atividades de otimização e planejamento." A implementação dos indicadores garantem que o processo será avaliado constantemente, tornando assim mais difícil qualquer falha ou perda de valor do mesmo. Esses indicadores podem seguir diferentes tipologias, visando avaliar de uma forma global a eficiência e eficácia do processo, segundo Valle e De Oliveira (2013) "Quanto à tipologia, um indicador pode ser quantitativo, qualitativo ou quati-qualitativo." No presente estudo foram propostos indicadores quantitativos e qualitativos, mas a frente eles serão descritos e justificados.

Uma ferramenta que irá ajudar muito no objetivo do estudo em questão será o mapeamento de processos. Serão apresentados em seguida alguns parágrafos para explicar um pouco melhor o conceito.

\subsubsection{Mapeamento de processos}

O mapeamento de processos é uma técnica muito comum nas empresas de hoje. É uma ferramenta que ajuda os gestores a entender de forma clara como uma unidade de negócios está operando, representando cada passo de operação dessa unidade em termos de entradas, saídas e ações. A ferramenta de mapeamento de processos é fundamental para a melhoria nos processos organizacionais, pois é a partir de um mapa de processos bem estruturado que as sugestões de melhoria e pontos de atuação que podem ser elencados e observados mais detalhadamente.

O primeiro passo para iniciar um mapa de processo é entender o que está sendo mapeado e a razão desse mapeamento. Isso parece óbvio mas muitas organizações não conseguem encontrar os limites dos seus processos, ou seja, aonde começa e termina um processo e começa um outro, e também quais são as suas entradas e saídas. Uma vez entendidos os limites do processo e suas entradas e saídas, e, claro, o objetivo final do mapeamento, o próximo passo será determinar qual é o nível de detalhe do mapa do processo. Em 
alguns casos, um nível de detalhamento muito grande pode prejudicar o entendimento do processo.

Após esse entendimento do que temos hoje, é necessário o mapeamento de como o processo é hoje, ou seja, As Is. Para depois ser possível a análise de possíveis melhorias chegando no novo mapa, também chamado pelos estudiosos de To Be.

Essa delimitação do nível de detalhe da análise ajuda na construção de uma cultura contínua de verificação e validação dos mapas internos construídos. Verificar o mapa é nada mais que garantir que nenhum erro de representação foi cometido, seja com ícones, legendas, fluxos de atividades etc. Já a validação trata de garantir que o mapa construído representa a realidade do sistema estudado; é a etapa mais difícil do mapeamento, pois, segundo Michael Hammer (1994), "existem 3 versões do processo estudado : o que se pensa que ocorre no processo, o que realmente ocorre no processo e o que deveria ocorrer no mesmo. Quem realiza o mapeamento deve se ater exclusivamente ao que realmente ocorre no processo, para numa etapa posterior entender o processo e aí sim propor modificações e melhorias, o que exige acompanhamento de todo o fluxo de atividades constantemente." 


\section{Métodos e procedimentos de coleta e de análise de dados} do estudo

Este capítulo se propõe a identificar e justificar quais foram os métodos de pesquisa utilizados durante o estudo. Além disso, são formalizadas as limitações derivadas da metodologia de pesquisa utilizada para a confecção do estudo.

Segundo Vergara (1997) "Para a realização de uma pesquisa, é necessário primeiramente dois critérios básicos : quanto aos seus fins e quantos aos seus meios." Para o presente estudo com relação aos seus fins, ele é classificado como descritiva, pois se propõe a entender todo um processo já existente e captar as atuais percepções dos seus usuários com relação a ele. Segundo Vergara (1997), "A pesquisa descritiva expõe características de determinada população ou de determinado fenômeno. Pode também estabelecer correlações entre variáveis e definir sua natureza. Não tem compromisso de explicar os fenômenos que descreve, embora sirva de base para tal explicação. Pesquisa de opinião insere-se nessa classificação.". Quanto aos meios, como o pesquisador trabalha na empresa em que o processo estudado acontece ela é participante, como são usados livros de autores para responder a questão principal do trabalho ela é bibliográfica, por serem usadas informações retiradas de dados secundários de documentos da Puig Basil ela é também documental e por fim por se tratar de uma pesquisa de opinião realizada através de entrevistas ela é qualitativa.

Zikmund (2006) "Dados secundários são informações previamente coletados e registrados por alguém ou alguma organização com objetivos diferentes dos que estão sendo pontuados no projeto atual."

O setor escolhido de perfumaria foi selecionado porque é um mercado que está em constante crescimento no Brasil, segundo a ABIHPEC (2015) Associação Brasileira da Indústria de Higiene Pessoal, Perfumaria e Cosméticos. O Brasil é líder global no mercado de cosméticos, com um faturamento que chega $\mathrm{R} \$ 17$ Bilhões. Um dos principais players desse mercado é a Puig com marcas renomadas como Carolina Herrera e Paco Rabanne. Por isso ela foi selecionada como objeto deste estudo.

Para melhor entendimento este capitulo está dividido em cinco seções que informam, respectivamente, sobre as etapas de coleta de dados do estudo 
realizado, sobre as fontes de informação selecionadas para coleta de informações neste estudo. Na sequência, informa-se sobre os processos e instrumentos de coleta de dados realizados em cada etapa, com respectivas justificativas, sobre as formas escolhidas para tratar e analisar os dados coletados e, por fim, sobre as repercussões que as decisões sobre o estudo impuseram aos resultados obtidos.

\subsection{Etapa de coleta de dados}

Para a pesquisa bibliográfica foram coletados dados através de alguns livros, como: Além da Reengenharia e Organização Flexível, e alguns artigos publicados, sites relacionados a processos organizacionais, algumas dissertações, informações publicadas pelo órgão responsável sobre o setor de perfumaria e cosméticos. A parte documental coletou dados nas fontes internas da organização estudada; foram levantadas sua história e contexto, consultando publicações internas, publicações da empresa e relatórios internos. Como o pesquisador tem acesso a essas informações por trabalhar na empresa em questão, essa etapa foi realizada de forma fácil.

As etapas descritas acima se tornaram justificáveis, pois permitiram a identificação de questões entre a teoria e prática para a elaboração mais assertiva dos roteiros das entrevistas. Enriquecendo assim a contribuição desse trabalho para a empresa.

Após isso, foi realizada uma pesquisa qualitativa descritiva. Foram realizadas sete entrevistas. Elas foram conduzidas pessoalmente, com integrantes de diferentes áreas dentro e fora da organização que utilizam o processo regularmente. $\mathrm{O}$ objetivo foi entender as reais percepções do processo estudado, com total imparcialidade, obtendo informações de óticas de diferentes percepções e obtendo assim o máximo de informação possível.

\subsection{Fontes de informação selecionadas para coleta de dados} no estudo. 
Para a coleta dos dados secundários externos, foram utilizadas pesquisas bibliográficas em livros que abordavam o tema, além de fontes digitais que tinham conteúdo relevante para a pesquisa, e ainda dados sobre o setor, disponibilizados pela ABIHPEC, órgão que reúne informações variadas sobre o assunto. Para dados secundários internos, foi abordado site da Puig e também material interno da organização. Essas fontes foram selecionadas por passar a imparcialidade desejada para o estudo e por proporcionar um panorama geral de gestão por processo, e afinal evidenciar formas de otimização do caso da Puig Brasil.

As entrevistas realizadas foram feitas com indivíduos que utilizam regularmente o processo, pessoas de diferentes níveis hierárquicos dentro e fora da empresa. Buscou-se obter diferentes visões sobre o processo, enriquecendo ainda mais este estudo.

Elas foram divididas basicamente em 3 grupos, tendo cada grupo seu questionário diferente. Os grupos foram: os operadores do processo, os clientes internos do processo e os clientes externos do processo. Ou seja, todos os grupos tem relação direta com o desenvolvimento do processo e resultados finais.

O primeiro grupo foi constituído por Ana Carolina Damazio e Suane Araujo, que são assistente e analista, respectivamente da área de contas a pagar e que já trabalham com o processo por cerca de 2 anos. Já o segundo grupo englobou 3 pessoas: Naiara Lopez, estagiária da área de marketing, Nathalia Tavares, analista da área de trade marketing e Renata Monteiro, gerente de produto na área de marketing - todas elas utilizam o processo regularmente em média há 2 anos e já têm bastante informações sobre o mesmo. O terceiro grupo de clientes externos tem um total de 2 pessoas. Lene Silva e Lucas Novo, que são parte importante dos fornecedores mais significantes da Puig atualmente.

Todas as fontes de dados escolhidas descritas acima foram selecionadas por conveniência, pois o autor do estudo tinha fácil acesso a elas durante o período de realização do trabalho.

3.3. Procedimentos e instrumentos de coleta de dados utilizados no estudo. 
No primeiro momento, para a obtenção dos dados secundários foram feitas pesquisas em cima de informações públicas da organização selecionada, e também buscas a documentos internos sobre o setor de perfumaria, no qual a empresa se insere. Além de pesquisas bibliográficas em livros de diferentes autores de administração de empresas.

Já para a coleta de dados primários foram feitas entrevistas para validar o que foi pesquisado nas etapas bibliográficas e documentais da pesquisa. As entrevistas foram realizadas no próprio ambiente de trabalho sem nenhum tipo de influência do pesquisador durante a entrevista, e deixando o entrevistado a vontade para pontuar o que quisesse. O roteiro foi confeccionado a partir das percepções do pesquisador durante a primeira etapa da pesquisa, o objetivo da entrevista é o de entender o atual nível de percepção dos usuários do processo, e após com isso determinar o atual nível de eficiência e eficácia do mesmo. As entrevistas foram marcadas com antecedência com os entrevistados, visto que existe uma alta carga de trabalho e as agenda estão sempre lotadas. O primeiro grupo de entrevistados teve em média uma conversa com duração de 40 minutos, documentadas e depois transcritas, em que o objetivo era o de entender na visão dos operadores do processo o atual nível de eficiência e de eficácia, o que eles julgam importante, o que eles gostariam que mudasse e o atual nível de satisfação. Como pode ser visto nos anexos do estudo.

Já as entrevistas com os clientes do processo visou descobrir os problemas do processo na visão deles, o atual nível de eficiência e eficácia e também o nível de satisfação, que no caso de clientes é de extrema relevância para o estudo. As entrevistas com os grupos de clientes foram um pouco mais demoradas e levaram em média 50 minutos, lembrando que documentadas e depois transcritas.

Os três questionários tiveram em média dez perguntas, como pode ser visto nos anexos do estudo, e tiveram a preocupação de ser tão abertas quanto possível, para que fosse possível captar a real percepção do entrevistado, registrando o que ele realmente acha sobre o assunto.

\subsection{Formas de tratamento e análise dos dados coletados para} o estudo. 
Os dados coletados foram tratados de forma qualitativa pelo pesquisador. Elas foram feitas de duas formas diferentes.

Na primeira etapa as informações foram obtidas através de pesquisas e estudos, utilizando como base dados internos e secundários. Eles sofreram uma análise de conteúdo, pois eles foram usados para ajudar o pesquisador a se preparar para a elaboração dos roteiros das entrevistas, visto que no primeiro momento o objetivo era o de obter o máximo de informação possível sobre o tema estudado.

$\mathrm{Na}$ segunda etapa, a coleta dos dados foi obtida por meio de 7 entrevistas com pessoas diretamente relacionadas com o processo de contas a pagar da Puig Brasil, os dados foram tratados por meio de uma analise qualitativa, foram confeccionados relatórios de opinião do pesquisador sobre as respostas obtidas, todas as respostas foram devidamente escritas e documentadas, a opinião do pesquisador também foi levada em consideração, visto que o mesmo conhece o dia a dia da organização, e também se esforçou de todas as formas para se manter o mais imparcial possível durante as entrevistas, a fim de não comprometer a relevância do estudo.Todas as análises foram autorizadas pelos responsáveis das respectivas áreas, mantendo sempre a base de dados com confiança máxima. Após isso foi realizado um cruzamento entre as teorias abordadas durante o estudo e as respostas obtidas nas entrevistas com os usuários do processo estudado.

\subsection{Limitações do Estudo}

Foram identificadas algumas limitações para a metodologia escolhida que podem acabar por distorcer os resultados finais da pesquisa realizada. Identificase como limitação da metodologia: a seleção dos sujeitos para a realização das entrevistas que foi feita por conveniência do pesquisador. Dessa forma, não será possível garantir que os resultados da pesquisa representem a PUIG Brasil e o mercado como um todo. Outra limitação observada é o fato de poucas empresas estarem dentro do estudo em questão.

$\mathrm{Na}$ etapa de coletas de dados secundários, por se tratarem de dados já existentes, não podemos dizer que estão totalmente fiéis a realidade. Por outro 
lado como o pesquisador esta inserido no ambiente da pesquisa, coube a ele filtrar o que usar e o que não usar.

$\mathrm{Na}$ etapa descritiva a parte de coleta de dados feita através das entrevistas pode haver um certo grau de subjetividade e influência do pesquisador nas interpretações das respostas. No caso das entrevistas dentro da Puig Brasil, a restrição de tempo do funcionário em questão pode limitar a profundidade das entrevistas e o tempo possível para a sua realização.

\section{Resultados}


Este capítulo tem como objetivo apresentar e analisar os principais resultados gerados a partir da pesquisa realizada e mostrar como esse material será utilizado para otimizar o processo de contas a pagar da Puig Brasil. Ele está divido em 4 etapas.

A primeira etapa consiste na apresentação do contexto da empresa Puig e suas operações no Brasil. São mostrados dados históricos da empresa, bem como dados financeiros e de mercado relevantes.

A segunda etapa será a apresentação do diagrama de contexto do processo, onde todos os detalhes do processo são descritos e pontuados. Bem como sua utilização, objetivos, controles entre outros aspectos.

$\mathrm{Na}$ terceira parte, foram feitas as análises das entrevistas realizadas com funcionários que tem relação diária com o processo estudado. Bem como o devido cruzamento das respostas com as teorias abordadas anteriormente durante o trabalho.

A última etapa, após toda a análise realizada, aponta sugestões para a melhoria do processo, com base nos resultados obtidos nas entrevistas, nas teorias aplicadas. Esse capítulo irá responder o problema proposto por este trabalho, indicando como tornar o processo de contas a pagar da Puig Brasil mais eficiente e eficaz em diferentes percepções de diferentes usuários.

\subsection{A Empresa Puig Brasil}

A Puig é uma multinacional barcelonense que desenvolve sua atividade voltada para dois pilares: moda e perfumes. A empresa foi fundada em 1914 por Antonio Puig e segue sendo administrada pela família. Ela é dona de marcas em importantes no mercado como Carolina Herrera, Paco Rabanne e Nina Ricci, entre outras. Em 2014, a empresa conquistou a importante marca de 100 anos de existência, feito bastante comemorado internamente pela empresa. Marc Puig é o CEO na atual etapa da empresa..

A Puig comercializa seus produtos em 140 países e em 22 deles ela tem pelo menos uma subsidiária. Ela emprega atualmente um total de 4.197 funcionários ao redor do mundo. Segundo as demonstrações da empresa, sua receita liquida no ano de 2014 fechou com a incrível marca de 1,508 bilhões de 
euros e seu lucro líquido com o total de 177 milhões de euros. Em 2010 a empresa alcançou um market share, no mundo de fragrâncias, de 7,6 \%

No Brasil, a Puig iniciou sua atividade em 2008. Conta hoje com cerca de 300 funcionários no país, afora a mão de obra terceirizada, sendo liderada por sua general manager, Simone Duallibi. Aqui, o carro chefe da empresa é a perfumaria, segmento em que a empresa concentra a maior parte de seus recursos, tendo em vista o grande potencial que apresenta em nosso país. A vertente de cosméticos também está conquistando relevância dentro da organização, para isso marcas como Clarins e Chanel Cosmetics começaram também a ser distribuídas pela Puig Brasil.

No ano de 2014, a empresa, no Brasil, obteve uma receita líquida de $\mathrm{R} \$$ 222.745.825,00, um crescimento de $26 \%$ em relação a 2013. Até o momento (Outubro de 2015) ela conta com uma receita de $\mathrm{R} \$ 173.538 .506,00$. Sua estrutura é mais concentrada na força de vendas, marketing e operações logísticas. Isso é natural uma vez que sua estrutura de produção é toda internacional, todos os produtos comercializados são importados. Apenas a produção de materiais de ponto de venda, merchandising e administrativos é realizada localmente, com fornecedores escolhidos pela filial.

\subsection{O Processo de Contas a Pagar}

Para atender ao objetivo do trabalho que foi apontado e explicado ao longo do estudo. Vamos identificar todas as fases do processo em questão, agentes internos e externos, interfaces tecnológicas e atividades.

Primeiramente foi abordado o diagrama de contexto do processo, que, segundo o guia PMBOK (2009), "é o diagrama de contexto que mostra como um sistema de negócios/processo se relaciona com outras entidades externas."

Abaixo segue um esboço do que seria o diagrama de contexto do processo estudado: 


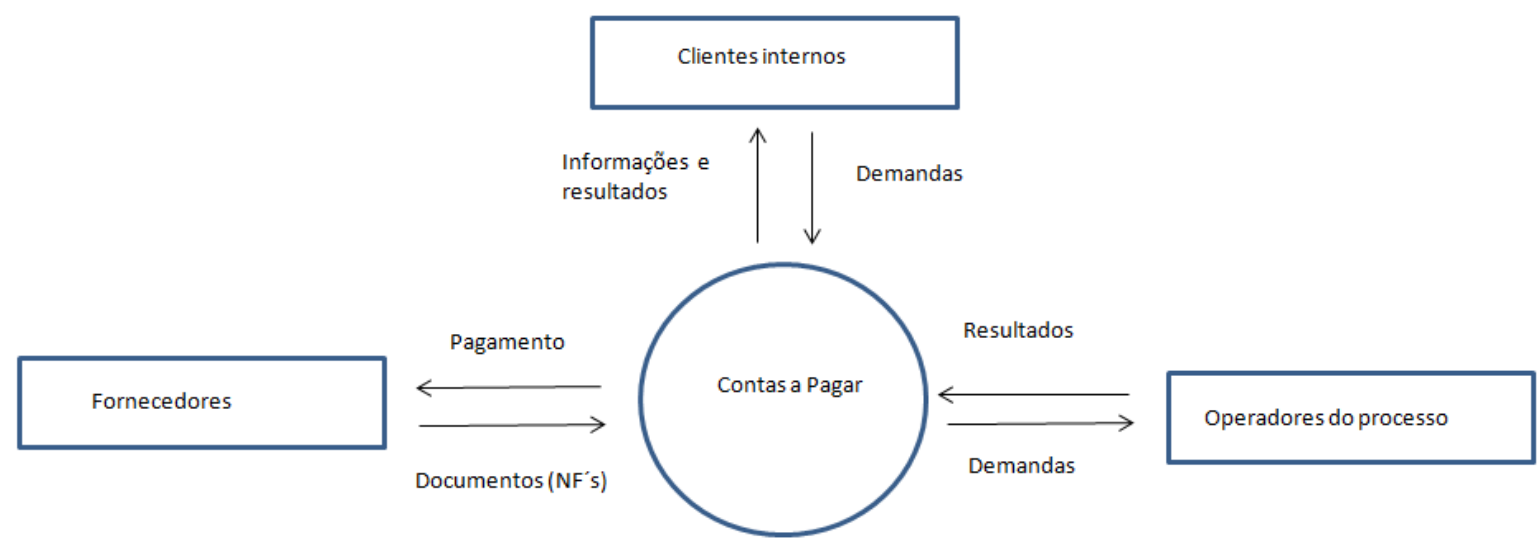

Figura 2: Diagrama de Contexto do Processo (Gabriel Lemos, 2015)

Analisando o esquema acima, vemos que existem 3 esferas que influenciam diretamente o processo objeto do estudo. Primeiramente, temos os clientes internos que começam todo o processo de contas a pagar, eles solicitam sempre o que tem que ser pago pelo contas a pagar, que passa isso para os seus operadores internos, para que assim realizem todo o restante do processo até chegar ao pagamento do serviço/produto solicitado.

As setas indicam o fluxo de informação que gira em torno do processo de contas a pagar, e quem de onde ele vem e para onde vai. Essa noção macro do processo é importante para o seu posterior detalhamento no mapa do processo.

Após as entrevistas realizadas e o levantamento dos dados para a realização do estudo pelo pesquisador, o processo foi desmembrado e descrito em diferentes partes. Na maneira em que ele existe hoje, podemos resumi-lo da seguinte forma : ele inicia no pedido aberto via o sistema integrado da empresa (SAP), gerado pelos clientes internos da organização, que chega a área financeira pelo mesmo sistema. Após isso, os fornecedores enviam a nota ou boleto ao contas a pagar, que confere se os dados lançados no sistema conferem com os dados dos documentos. Caso esteja tudo alinhado, o pagamento é realizado, mais à frente o processo será devidamente mapeado. $\mathrm{O}$ pagamento tem o prazo de 30 dias para ser realizado, a partir da abertura do pedido no sistema, isso é acordado com os fornecedores e clientes. Os 
depósitos ou transferências dos valores são realizados todas as segundas feiras das semanas.

Hoje, existem alguns indicadores para controle do processo, como explicado por Hammer (1994). Para ter excelência na gestão dos processos é preciso medi-los regularmente, e essa medição deve ser feita através de indicadores bem elaborados. No entanto, esses indicadores não são muito presentes na Puig. Existem hoje apenas 2 indicadores relacionados com o contas a pagar da empresa. Um deles é o total de processos finalizados por mês. Segundo dados internos da Puig, a empresa, no momento, trabalha com uma média de 80 pedidos por mês, que, com sazonalidades, chegam a 140 . Outro indicador existente hoje é o de pedidos realizados fora do prazo médio de 30 dias, que em média chegam 20 por mês, e que , com sazonalidades, chega a incríveis 50 pedidos por mês. Indicadores relacionados a satisfação do processo não são postos em prática pela empresa.

\subsection{Mapa do Processo}

Como pontuado e explicado, por Tashizawa (1996), o mapeamento do processo é ferramenta fundamental na sua otimização. Ele detalha cada atividade e etapa que o compõem. A seguir, está o mapa do processo as is, ou seja, da maneira em que ele funciona hoje em dia. Ele foi desenhado através do software de modelagem processual chamado Bizagi. Apenas para esclarecimento, foi usado o nome P.O para as ordens de pagamento emitidas (Purchase Order): 


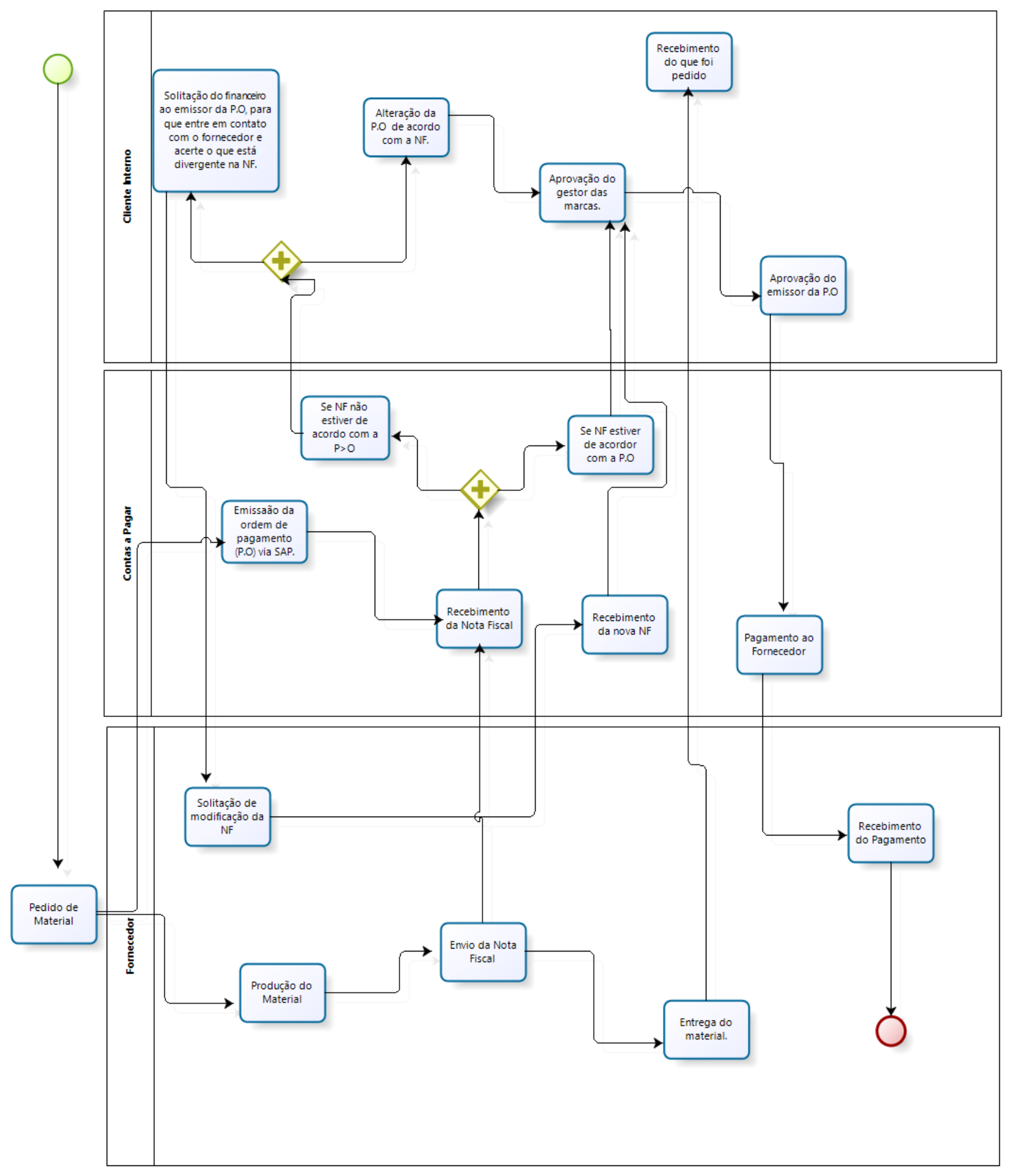

Figura 3: Mapa do Processo de Contas a Pagar As Is (Gabriel Lemos, 2015) 
Como pode ser visto no mapa, o processo corre em diferentes esferas desde o seu início até seu término. Isso não é bom, pois nesse caminho muitas informações podem se perder ou ser transmitidas de forma errada, causando retrabalho. Outro ponto relevante para ser analisado é a cadeia de aprovações realizadas, as quais estão deixando o processo mais lento, burocrático, e com maiores chances de atrasos ou erros.

Fazendo uma relação com o que foi escrito por Saulo Barbará (2009), esse cruzamento entre departamentos que está sendo evidenciado não é saudável para o resultado do processo, a menos que haja uma segurança da informação transmitida relevante. Como explicado no referencial teórico, eliminar ou modificar as atividades que não agreguem valor, ou seja, explicitamente retrabalho, é essencial para otimizar um processo de negócios .

\subsection{Análise das Entrevistas}

Analisando as entrevistas realizadas para a confecção deste trabalho observamos que o grupo de operadores do processo, vê que atualmente o mesmo é bastante burocrático e que uma mudança nesse aspecto poderia melhorá-lo. Outro ponto observado foi a questão do fluxo de informação dentro do processo. Parece que não há um sincronismo entre as partes envolvidas no que se refere às informações transmitidas, isso é um ponto que deve ser trabalhado de maneira mais assertiva internamente. Como já ressaltado pelo autor Michael Hammer (1994), a aplicação de indicadores é essencial para o controle de processos organizacionais. Para o grupo de operadores, seria interessante a aplicação de um indicador de satisfação dos resultados encontrados. Isso realmente é algo que está faltando dentro da Puig Brasil, o pesquisador obsevou ao longo das entrevistas que esses indicadores não são internalizados pelo grupo de funcionários. Outro ponto levantado pela entrevistada Suane Araujo, é a relação de erros no manejo do sistema de gestão da empresa, que acontecem, na opinião dela, por falta de treinamento dentro da empresa. Atualmente existem treinamentos sobre o assunto para novos funcionários, mas não há reciclagem para os colaboradores antigos e, como o autor trabalha atualmente na empresa ele vê alguns problemas com relação a esse tema: existem falhas notórias nos treinamentos realizados, seja na escolha das pessoas que realizam o treinamento e no material disponibilizado para quem 
recebe o treinamento. Não existe uma apostila ou um material para que os novos funcionários tenham algo para consultar no dia a dia. Atualmente esse treinamento é organizado pela área de controladoria da Puig Brasil.

Passando para os clientes internos, nota-se que os problemas com as entregas acontecem mais do que o esperado. Como pode ser visto nas entrevistas em anexo, o problema com a burocracia é citado novamente, e é uma oportunidade de melhoria notória dentro do processo. O fluxo de informações também é mostrado como gerador de problemas dentro do processo, o que deve ser revisto; mais à frente será apresentada uma forma de controlar esse ponto. Para este grupo, vemos tendência para a aplicação de indicadores de satisfação dos resultados, o que hoje não existe na organização. Para esse grupo vemos uma preocupação com os resultados do processo, todos os entrevistados apontam o processo estudado como estratégico para cada área. Conclui-se que o atual nível de eficiência e eficácia do processo não é dos melhores para os clientes internos.

Analisando as entrevistas realizadas com o grupo dos clientes externos (fornecedores), entendemos que alguns pontos devam ser destacados. Foram escolhidos fornecedores que entregam produtos e serviços da maior relevância para a organização. Sendo assim, deveriam ser objeto de atenção diferenciada por parte da organização, nas suas diferentes áreas e diferentes níveis hierárquicos. Os resultados recebidos mostram que essa relevância não é reconhecida pela empresa. Esses fornecedores não se sentem adequadamente valorizados e o fluxo das operações não fica claro para eles. Quando existe algum tipo de problema durante o processo eles não sabem a quem procurar e acessam pessoas que não detém o conhecimento necessário para orientá-los. Como descrito no referencial teórico, o fluxo de informações tem que ser claro para evitar e mitigar problemas ao longo do processo. Vemos ainda que, na opinião deles, indicadores de satisfação dos fornecedores seriam uma ótima iniciativa. Também reduções de prazo são mencionadas como desejáveis. Quanto ao nível de satisfação desses parceiros, o quadro não é animador. Erros recorrentes são apontados em ambas as entrevistas. Por fim o atual nível de eficácia e eficiência não é bom segundo este grupo de entrevistados, para eles existem pontos a serem melhorados internamente e externamente. 


\subsection{Proposta}

Primeiramente, revisitando o que já foi dito no referencial teórico pelos autores abordados - Hammer (1994) e Valle e De Oliveira (2013), é fundamental a doção da tríade planejamento, execução e controle, nos processos, para que se obtenham resultados satisfatórios. Após a análise de todas as informações coletadas para a confecção deste trabalho, percebemos algumas falhas em cada passo descrito acima.

Falando primeiramente do planejamento, existem falhas no que se refere à preparação dos funcionários que vão utilizar o processo, ou seja, os treinamentos realizados para ensinar as pessoas a utilizar a interface do sistema (SAP) não estão sendo executados da melhor maneira. O sistema utilizado na Puig Brasil para organização de dados é um dos melhores do mundo, o conhecido SAP. A causa dos erros recorrentes que acontecem não está no sistema e sim em quem o usa, e mais ainda na preparação das pessoas que o utilizam. Proponho uma troca dos responsáveis pelos treinamentos das pessoas que utilizam o processo. Hoje, tais treinamentos são ministrados pela área de controladoria da empresa, mas penso que ele devam aplicados e esquematizados pelo próprio contas a pagar da empresa, visto que aí estão as pessoas que sabem os detalhes do dia a dia do processo, que conhecem os problemas recorrentes e as dificuldades dentro do processo. Além disso, deve ser confeccionado um material com os detalhes mais importantes sobre o processo, para ser disponibilizado para todos esses funcionários que usam o processo. Esse material deve ser feito da maneira mais explicativa possível para que não exista dúvida quando ele for usado para consultas. Com isso, os erros recorrentes que foram mencionados serão amenizados até chegar o momento em que sejam reduzidos a 0 .

Analisando a parte operacional do processo, vemos problemas com a burocracia e com relação ao fluxo de informações, em especial o trâmite de aprovações das ordens de pagamento. Nossa proposta é organizá-lo de outra forma. Como estamos lidando com verbas estipuladas pela matriz, os gestores das áreas têm que saber o que estão gastando, mas não necessitam aprová-las, o que atrasa o processo, uma vez que eles nem sempre estão disponíveis para esse fluxo de aprovações, que, dependendo da área, é enorme. O esquema de aprovações deveria ser: até $\mathrm{R} \$ 5.000$, aprovação do analista mais sênior da área, que pode esclarecer qualquer dúvida que o gestor tenha referente a esses 
gastos; de $\mathrm{R} \$ 5.000$ a $\mathrm{R} \$ 20.000$, passar pelo crivo do gestor da área; de $\mathrm{R} \$ 20.000$ a $\mathrm{R} \$ 100.000$, a alçada passa para a diretoria que solicitou o pagamento, e acima de $\mathrm{R} \$ 100.000$ haveria a exigência de aprovação por parte da Gerência Geral da empresa. Assim, conferimos agilidade aos processos rotineiros e elevamos o grau de relevância dos pedidos mais estratégicos e de maior valor financeiro. Com relação ao fluxo de informação interno ao processo, o problema é que o processo cruza vários departamentos até chegar ao seu resultado final. A proposta é documentar o fluxo de informação e associar a cada natureza de problema a área que deve ser solicitada para solucioná-lo. Por exemplo, problemas na produção devem ser direcionados para o marketing, problemas de natureza financeira, como datas de pagamentos, dúvidas sobre notas fiscais ou boletos devem ser diretamente direcionados para ao setor financeiro. Seria, ainda, importante indicar nesse documento a quem essas dúvidas serão direcionadas - e divulgar essa informação para todos os envolvidos. Assim, os problemas serão resolvidos mais rapidamente e com menor risco de equívoco.

Quanto à parte de controle, ela é a final, mas não é menos importante, pois é ela que garante que tudo esteja sendo realizado da maneira planejada.

Como destacado durante o estudo, não há registro e acompanhamento de indicadores para controle das atividades do processo de contas a pagar, de forma estruturada e alinhada aos objetivos estratégicos da organização. Após a análise das entrevistas e de todas as informações coletadas durante o estudo, alguns indicadores foram propostos, para o acompanhamento do processo.

Dividimos os indicadores em dois grupos. O primeiro é o quantitativo, para esse os novos indicadores propostos são: (1) a razão entre os pedidos de pagamentos abertos no mês e os pedidos abertos no mês anterior; este indicador visa a mensurar a evolução do fluxo de trabalho durante os meses do ano, conseguindo assim enxergar as oscilações durante o ano (sazonalidades). Outro indicador (2) a ser avaliado seria o total de pedidos abertos, de modo a permitir um planejamento anterior das áreas, quando o fluxo for muito grande ou muito pequeno. O segundo grupo seria o qualitativo. Seu primeiro indicador (1) é o que compõe a razão entre os pedidos abertos durante o mês sobre o total de pedidos abertos e o segundo (2) seria a razão entre os pedidos fora do prazo sobre o total de pedidos. Finalmente, indicadores de satisfação dos clientes 
internos e externos: uma pesquisa pequena e aberta seria disponibilizada para eles periodicamente para descobrir a real satisfação dos envolvidos.

Com essas mudanças descritas acima os principais problemas identificados durante o processo seriam minimizados e mitigados, tornando mais difícil sua ocorrência.

Abaixo, está representado como ficaria o processo devidamente modificado como descrito, o mapa to be do processo estudado.

Proposta do processo de contas a pagar da Puig Brasil - To Be: 


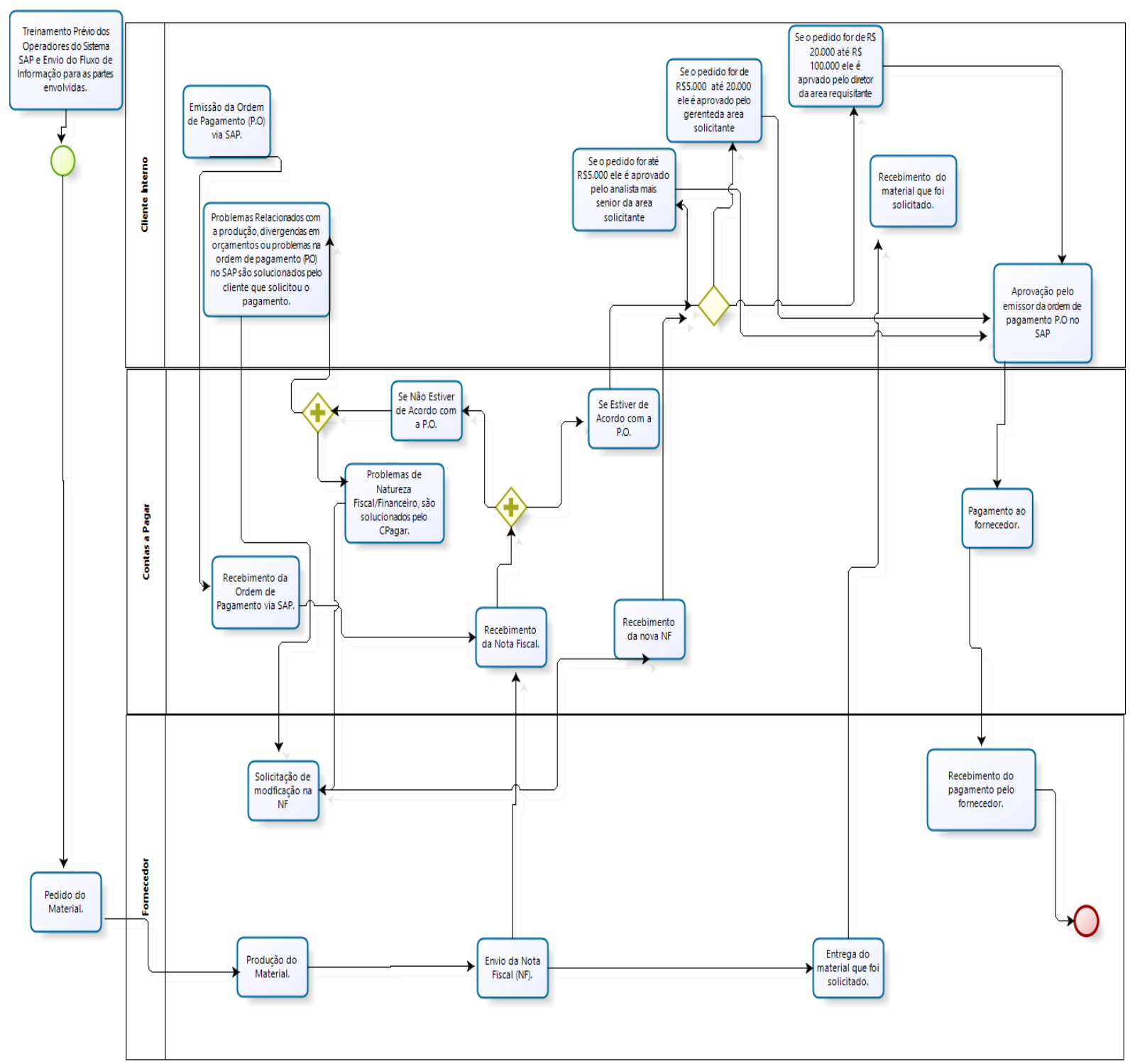

Figura 4: Mapa do Processo de Contas a Pagar To Be (Gabriel Lemos, 2015) 


\section{Conclusões}

O presente estudo se propôs a identificar e pontuar o real nível de eficiência e eficácia do processo de contas a pagar da empresa Puig Brasil, e após essa definição propor maneiras de otimizá-lo. A otimização é um desafio estratégico tendo em vista o grande acirramento da concorrência dentro do mercado e a acelerada globalização ao redor do mundo.

No primeiro momento, foram pesquisados, através de pesquisas bibliográficas, com acesso a dados internos da organização Puig Brasil, também dados sobre o setor de cosméticos e perfumaria retirados do órgão Associação Brasileira da Industria de Higiene Pessoal, Perfumaria e Cosméticos, 2015 (ABIPHEC) e sites como Sebrae e Exame.com. Essa primeira pesquisa foi realizada a fim de gerar conhecimento suficiente para orientar o estudo do caso PUIG Brasil. Na etapa seguinte, foram pesquisadas teorias sobre gestão de processos elaboradas por diferentes autores. Primeiramente foi abordado o conceito de reengenharia organizacional de Hammer (1997) e Morris e Brandon (1993). Em seguida, passamos para a organização flexível, como descrita por Tashizawa (1996). Por fim foi abordado o conceito de Business Process Modeling (BPM), como apresentado por Valle e De Oliveira (2013).

A fim de chegar aos objetivos pretendidos foi realizada uma pesquisa qualitativa baseada em 7 entrevistas em profundidade, as quais foram dividias em 3 grupos. Os grupos foram divididos visando absorver a percepção de diferentes classes de usuários do processo estudado. Os grupos foram divididos da seguinte maneira: clientes internos do processo, os operadores do processo e os clientes externos do processo (fornecedores). Os grupos respondentes desses grupos foram escolhidos visando abraçar os diferentes níveis hierárquicos dos grupos, a fim de obter a real percepção do processo em seus diferentes níveis de atuação.

Os dados coletados foram tratados da melhor maneira a fim de responder aos questionamentos indicados no problema deste estudo. Foram obtidas conclusões bastantes satisfatórias a partir desses dados e as perguntas foram devidamente respondidas. 
Os conceitos utilizados durante o estudo foram de bastante relevância para a obtenção das conclusões. Após as pesquisas realizadas e a análise dos dados coletados, alguns pontos ganharam relevo adicional, do ponto de vista de sua importância para as mudanças pretendidas, tanto no planejamento do processo, na execução e no controle. Na etapa de planejamento foram detectadas falhas na preparação do material humano para a utilização da interface sistêmica do processo (SAP); foi sugerida a realização de treinamentos mais assertivos com a utilização de manuais e guias passo a passo. Já na etapa de implementação, foram destacados durante as entrevistas notórios problemas relacionados ao fluxo de informações dentro do processo. Na etapa de controle, em consonância com o referencial teórico, foi indicado o uso constante de indicadores de desempenho tanto quantitativos como qualitativos.

\subsection{Sugestões e recomendações para novos estudos.}

Primeiramente, fica indicada como sugestão para trabalhos futuros uma comparação entre processos de outros setores da economia dentro do nosso país, mais especificamente a comparação com setores que vão bem em seus negócios a despeito da presente crise vivida no país.

Uma segunda sugestão seria encontrar no mercado empresas que utilizam a gestão por processos em seu dia a dia e identificar semelhanças e diferenças que permitam identificar melhorias adicionais a introduzir nos processos da PUIG Brasil. Essa análise não foi realizada dada a dificuldade do pesquisador em encontrar no Brasil empresas relativamente semelhantes com a organização estudada e que fizessem uso de tal abordagem presentemente.

Como terceira recomendação, seria interessante a comparação com diferentes processos dentro e fora da empresa, a fim de perceber se o dia a dia da organização está alinhado com os objetivos do mercado e com o planejamento estratégico da própria empresa. Assim, o benchmarking, fortemente sugerido dentro do referencial teórico, ficaria mais completo. 


\section{Bibliografia}

MORRIS, Daniel \&Brandon, Joel. Reengenharia - Reestruturando sua empresa. Editora Makron Books, 1993.

VERGARA, Constant Sylvia - Projetos e Relatórios de Pesquisa em Administração. São Paulo. Editora Atlas, 1997.

TASHIZAWA, Takeshy. Organização Flexível - Qualidade na gestão de processos. São Paulo. Editora Atlas,1996.

GONÇALVES, José Ernesto Lima. As empresas são grandes coleções de processos. RAE - Revista de Administração de empresas. São Paulo, v.40, n.1, p. 6-19, jan/mar, 2000a.

GONÇALVES, José E. L. Reengenharia das Empresas: Passando a limpo. São Paulo: Atlas, 1995.

HAMMER, Michael. Alem da Reengenharia: Como Organizações Orientadas Para Processos Estão Mudando Nosso Trabalho e Nossas Vidas. Editora Campus,1997.

\section{Guia BPM CBOK (2009)}

ZIKMUND, W. G. Princípios da Pesquisa de Marketing. 2 Ed. São Paulo: Pioneira Thomson Learning, 2006.

VALLE, Rogério e DE OLIVEIRA, Barbará Saulo (Organizadores). Análise e Modelagem de Processos de Negócio : Foco na Notação BPMN (Busness Process Modeling Notation). São Paulo. Editora Atlas, 2013.

DRUCKER, Peter. Frases de Peter Drucker, Rio de Janeiro, 03 de maio de 2005. Disponível em: http://www.administradores.com.br/frases/peter-drucker. Acesso em 30 de outubro de 2015.

PERSPECTIVAS de mercado até 2015: higiene pessoal, perfumaria e cosméticos. Sebrae, São Paulo, 03 Nov 2014. Disponível em :http://www.sebraemercados.com.br/perspectivas-de-mercado-ate-2015-higienepessoal-perfumaria-e-cosmeticos. Acesso em 29 de setembro de 2015. 


\section{ANEXO 1}

Entrevista Operador do Processo 1

Assistente contas a pagar

1. Qual seu Nome?

- Ana Carolina Damazio

\section{Qual a sua idade?}

-21 anos.

3. Há quanto tempo você utiliza o processo de contas a pagar da PUIG Brasil ?

- Trabalho com o processo de contas a pagar da Puig desde que comecei a trabalhar na empresa, primeiramente como cliente, e depois quando me transferi para o contas a pagar trabalho diretamente todos os dias com o processo.

\section{Você apontaria alguma mudança para melhora-lo ? Se sim, Qual ?}

- Sim, penso que uma mudança que efetivamente representaria uma mudança significativa dentro do resultado final do processo seria a mudança das aprovações das ordens de pagamento. Hoje em dia ela é feita pelos gerentes e diretores, que as vezes não tem tempo de realizar as aprovações solicitadas e acabam atrasando os pagamentos para fornecedores e pagamentos.

5 . Numa escala de 1 a 5 , sendo 1 muito burocrático e 5 pouco burocrático, qual o nível de burocracia você apontaria dentro do processo ? Por que?

- 2, pois acho que ordens simples de pagamento passam por diferentes níveis hierárquicos até serem liberadas.

\section{O fluxo de informação dentro do processo é claro para você ?}

- Não, na maioria dos casos eu não sei do que esta se tratando o processo. Isso atrapalha pois as vezes sabendo o que esta sendo pago, podemos ajudar no contato com o fornecedor/cliente.

7 . Cite 3 fatores que na sua opinião podem comprometer o resultado final do processo.

- Atrasos na chegada das notas fiscais, atrasos nas aprovações e erros operacionais nas aberturas das ordens de pagamento. 
8. Numa escala de 1 a 5 , sendo 1 muito ruim e 5 ótimo, classifique e explique o nível de eficiência de eficácia do processo.

- 3, pois se tratando de eficiência penso que com a equipe que temos o trabalho é bem realizado, porem os resultados não são muito satisfatórios temos um prazo de 30 dias para fechar cada processo e isso não é cumprido na maioria dos casos.

9. Qual seria, na sua opinião, o melhor indicador para avaliar a eficiência e a eficácia do processo?

- Na minha opinião um indicador que melhor demonstra esses dois aspectos seria um indicador que unisse o nível de ordens de pagamento que são abertos e o nível de satisfação internamente e externamente.

Entrevista Operador do Processo 2

Analista Contas a Pagar

1. Qual seu Nome?

- Suane Araujo

\section{Qual a sua idade?}

-35 Anos

\section{Há quanto tempo você utiliza o processo de contas a pagar da PUIG Brasil ?}

- Já trabalho na empresa há 3 anos, e sempre trabalhei com o processo. Sempre fui operadora, pois sempre trabalhei na área financeira.

\section{Você apontaria alguma mudança para melhora-lo ? Se sim, Qual ?}

- Acho que é necessária uma mudança não dentro do processo, mas sim antes dele. Quero dizer que é preciso um melhor treinamento dos usuários dos processos, erros bobos e recorrentes sempre surgem e isso toma muito tempo do processo e consequentemente da área de contas a pagar da Puig.

5 . Numa escala de 1 a 5 , sendo 1 muito burocrático e 5 pouco burocrático, qual o nível de burocracia você apontaria dentro do processo ? Por que?

- 2, acho que o processo de contas a pagar da empresa é bastante burocrático, mas acho que tem que ser realmente assim pois se tratam de recursos da empresa essas informações tem que circular nos cargos mais elevados da organização. $O$ fato da empresa estar muito ligada a matriz na Espanha faz com que ele seja bastante burocrático também. 


\section{O fluxo de informação dentro do processo é claro para você?}

- Esse é um aspecto que realmente deve ser melhorado internamente. O fluxo de informação dentro do processo se perde muitas vezes, isso tem que ser melhor desenhado, pois esse processo na minha opinião é bastante relevante para as operações da Puig Brasi.

7. Cite 3 fatores que na sua opinião podem comprometer o resultado final do processo.

- Erros operacionais nas emissões das ordens de pagamento no SAP, problemas dentro do fluxo de informações durante o processo e atrasos/problemas por parte dos fornecedores/clientes.

8. Numa escala de 1 a 5 , sendo 1 muito ruim e 5 ótimo, classifique e explique o nível de eficiência de eficácia do processo.

- 4, dentro das realidade da empresa e do tamanho da nossa área (financeira) penso que realizamos um bom trabalho. Sei que não é perfeito pelos atrasos que acontecem, porem acho que a empresa é relativamente nova e acho que estamos no caminho certo.

9. Qual seria, na sua opinião, o melhor indicador para avaliar a eficiência e a eficácia do processo?

- Penso que o melhor indicador para controlar esses dois aspectos seria um que alinhasse o nível de reclamações dos clientes internos e externos com o objetivo operacional da área. 


\section{ANEXO 2}

\section{Entrevista Cliente Interno 1}

Estagiária Marketing

1. Qual seu Nome?

- Naiara Lopez

\section{Qual a sua idade?}

-25 anos.

\section{Há quanto tempo você utiliza o processo de contas a pagar da PUIG Brasil?}

- Eu uso o processo de contas a pagar desde que entrei na empresa, em novembro vou completar 2 anos dentro da Puig Brasil.

\section{Com que frequência você tem problemas com ele? Quais são eles?}

- Tenho problemas com uma frequência que não gostaria. Quase todo mês pelo menos uma das ordens de pagamento que abro no sistema (SAP) tem algum problema. Geralmente são problemas com notas fiscais que chegam na empresa com divergências e inconsistências do que esta no sistema ou problemas com atrasos nas aprovações dos respectivos gestores nas ordens.

\section{O fluxo de informação dentro do processo é claro para você?}

- Para mim o fluxo de informações dentro do processo é bastante claro, porem não se isso se repete nas outras esferas dele, pois é por aqui que começa todo o fluxo de atividades.

6. Numa escala de 1 a 5 , sendo 1 muito burocrático e 5 pouco burocrático, qual o nível de burocracia você apontaria dentro do processo ? Por que?

- 1, acho o processo de contas a pagar da Puig Brasil muito burocrático em aspectos que não deveriam ser. Como exemplo cito o nível das aprovações que tem que ser feitas para um simples pagamento recorrente de um contrato de mídia cooperada com um cliente, todo mês o gestor da área tem que aprovar algo que já esta previamente acordada entre ambas as partes.

\section{Você acha o processo é importante para o objetivo estratégico da sua área?}

- Sim, como temos poucos fornecedores dentro da empresa e precisamos deles com bastante frequência para produzir moveis, materiais, stands e etc... Acho que temos que ter o melhor relacionamento possível com eles, para que assim eles nos atendam da melhor forma e com o melhor preço.

8. Numa escala de 1 a 5 , sendo 1 muito ruim e 5 ótimo, classifique e explique o nível de eficiência de eficácia do processo. 
- 1, penso que existem muitas falhas dentro do processo, tanto no uso dos recursos necessários para executa-los quanto no nível de entrega final dos resultados. Muita coisa tem que melhorar.

9. Qual seria, na sua opinião, o melhor indicador para avaliar a eficiência e a eficácia do processo?

- Na minha opinião o melhor indicador para o processo seria o que medisse o atual nível de satisfação dos usuários do processo nos seus diferentes níveis hierárquicos.

10. Numa escala de 1 a 5 , sendo 1 muito ruim e 5 ótimo, classifique o nível de satisfação do processo e explique o porque desta nota.

- 2, acho que internamente os resultados finais do processo não são muito bons, pois sempre temos atrasos que desgastam a nossa relação com nossos fornecedores/clientes alem de sempre termos que ter retrabalhos por problemas de falta de comunicação.

Entrevista Cliente Interno 2

Analista Trade Marketing

\section{Qual seu Nome?}

- Nathalia Tavares

2. Qual a sua idade?

- 26 Anos

3. Há quanto tempo você utiliza o processo de contas a pagar da Puig Brasil?

- Uso o processo desde que entrei na empresa, em dezembro faço 3 anos de Puig Brasil.

4. Com que frequência você tem problemas com ele? Quais são eles?

- Todos os meses tenho problemas dentro do processo, sejam problemas internos como erros manuais dentro sistema, problemas com aprovações ou atrasos em pagamentos. $\mathrm{E}$ também externos como notas divergentes e problemas no fluxo de informações.

5. O fluxo de informação dentro do processo é claro para você?

- Não, acho que esse é um fator que complica bastante os resultados finais do processo. Após o lançamento dentro do SAP da ordem de pagamento, não sei os próximos passos. Somente que tenho que aprovar, se isso fosse compartilhado com o restante das pessoas o planejamento das aberturas poderia ser feita de forma diferente.

6. Numa escala de 1 a 5 , sendo 1 muito burocrático e 5 pouco burocrático, qual o nível de burocracia você apontaria dentro do processo ? Por que? 
- 3, acho o nível de burocracia do processo normal para o processo. Pois acho que esse processo por se tratar da verba da empresa para gastos variáveis, tem que ser acompanhado de perto pelos principais cargos da organização.

\section{Você acha o processo é importante para o objetivo estratégico da sua área?}

- Sim, a minha área é uma das que mais usa o processo, pois trabalhamos para todas as marcas da empresa. E produzimos materiais, stands, moveis entre outras coisas numa escala muito mais acelerada que nas outras áreas da empresa. Somos muito dependentes dos nossos fornecedores.

8. Numa escala de 1 a 5 , sendo 1 muito ruim e 5 ótimo, classifique e explique o nível de eficiência de eficácia do processo.

- 2, na minha opinião existem muitos pontos a melhorar dentro do processo desde aos meios utilizados para realização do mesmo, quanto a forma de entrega do resultado final aos seus clientes internos e externos.

9. Qual seria, na sua opinião, o melhor indicador para avaliar a eficiência e a eficácia do processo?

- Para mim o melhor indicador para avaliar esses aspectos seria um indicador que medisse a quantidade de ordens de pagamentos abertas e o nível de satisfação dos mesmo. Acho que esse indicador ajudaria muito no controle do processo.

10. Numa escala de 1 a 5 , sendo 1 muito ruim e 5 ótimo, classifique o nível de satisfação do processo e explique o porque desta nota.

- 2, penso que, pelo menos internamente, o nível de satisfação não é dos melhores. Devido aos atrasos recorrentes que acontecem e também pelos retrabalhos que também acontecem demais.

\section{Entrevista Cliente Interno 3}

Gerente de produto (Marca : Carolina Herrera)

\section{Qual seu Nome?}

- Renata Monteiro

\section{Qual a sua idade?}

- 33 Anos

\section{Há quanto tempo você utiliza o processo de contas a pagar da Puig Brasil?}

- Já estou a 3 anos na Puig Brasil, porem minha relação com o processo nunca foi diretamente. Geralmente peço para gerarem a ordem de pagamento, e depois controlo quanto ainda temos disponível para gastar. 


\section{Com que frequência você tem problemas com ele? Quais são eles?}

- Não vejo muitos problemas com relação ao processo. As vezes acontecem problemas mas isso é normal por ser um processo recorrente dentro da empresa.

\section{O fluxo de informação dentro do processo é claro para você?}

- Não, acho que o fluxo de informações do projeto se perde durante o processo pois ele atravessa diferentes áreas varias vezes.

6. Numa escala de 1 a 5 , sendo 1 muito burocrático e 5 pouco burocrático, qual o nível de burocracia você apontaria dentro do processo ? Por que?

- 3, acho que o nível de burocracia do processo esta em um nível aceitável. As vezes acho que alguns pontos são de difícil acesso dentro do processo, mas existem problemas que realmente tem que ser tratados de forma mais burocrática, ainda mais com a forte ligação da empresa com a sua sede na Espanha.

\section{Você acha o processo é importante para o objetivo estratégico da sua área?}

- Com certeza, como não temos um setor de compras interno e nem sistemas produtivos. Dependemos muito de nosso fornecedores, eles são mais que isso, são parceiros da Puig Brasil. Sem eles seria muito mais difícil manter a liderança de mercado que temos hoje em dia.

8. Numa escala de 1 a 5 , sendo 1 muito ruim e 5 ótimo, classifique e explique o nível de eficiência de eficácia do processo.

- 4, acho que dentro das dificuldades que uma empresa relativamente nova no mercado com a Puig Brasil, estamos bem com relação aos níveis de eficiência e eficácia. Conseguimos fazer muito com poucos recursos que temos disponíveis.

9. Qual seria, na sua opinião, o melhor indicador para avaliar a eficiência e a eficácia do processo?

- Para mim o melhor indicador para o processo é o que mensurasse o nível de satisfação dos usuários do mesmo, dentro e fora da empresa.

10. Numa escala de 1 a 5 , sendo 1 muito ruim e 5 ótimo, classifique o nível de satisfação do processo e explique o porque desta nota.

- 3, penso que existem problemas que atrapalham as entregas do processo, mas mesmo assim penso que o atual nível de satisfação é satisfatório de uma maneira geral. 


\section{ANEXO 3}

\section{Entrevista Cliente Externo 1 (Fornecedor)}

Comercial Empresa Imagemfix

\section{Qual seu Nome?}

- Lene Silva.

\section{Qual a sua idade?}

- 44 Anos.

\section{Qual seu cargo na empresa?}

- Trabalho no setor comercial, recebo todas as demandas dos clientes.

\section{Há quanto tempo você presta serviços para a Puig Brasil?}

- A empresa Imagemfix presta serviços para a Puig Brasil desde 2010.

5. Você considera seus serviços para a Puig Brasil como: Importante, relativamente importante ou facilmente substituível? Por que?

- Atualmente acho que temos uma relação forte com a Puig, eles são nossa principal conta e tomam cerca de $80 \%$ do nosso tempo de trabalho. E na minha visão atendemos muito bem eles, por isso acho que considero importante nossa participação dentro da empresa. Mais que fornecedores somos parceiros deles.

\section{O fluxo de informação dentro do processo é claro para você?}

- Por muitas vezes ficamos um pouco perdidos de quem procurar por diferentes problemas, isso penso que seja por falha no fluxo de informação. Acho que esse aspecto poderia ser melhor trabalhado por eles.

7. Numa escala de 1 a 5 , sendo 1 muito ruim e 5 ótimo, classifique e explique o nível de eficiência de eficácia do processo.

- Minha nota é 3, pois existem problemas recorrentes dentro do processo que acabam por atrasos alguns pagamentos que acabam atrapalhando nossas operações. Geralmente os problemas são os mesmos.

8. Qual seria, na sua opinião, o melhor indicador para avaliar a eficiência e a eficácia do processo?

- Na minha opinião para medir esses aspectos um indicador de satisfação dos fornecedores da Puig seria interessante para ser analisado. 


\section{Você apontaria alguma mudança para o processo? Por que?}

- Eu mudaria o tempo do processo que hoje em dia é de 30 dias, pois esse período é muito longo para nós. Visto que acontecem atrasos e imprevistos.

10. Numa escala de 1 a 5 , sendo 1 muito ruim e 5 ótimo, classifique o nível de satisfação do processo e explique o porque desta nota.

- Minha nota nesse quesito é 3, pois os problemas que geram a insatisfação são sempre os mesmo. Acho que eles devem ser pontuados e trabalhados para que não aconteçam mais. Porem de uma forma geral eles acontecem no prazo combinado.

Entrevista Cliente Externo 2 (Fornecedor)

Comercial Empresa RLM Displays

\section{Qual seu Nome?}

- Lucas Novo

2. Qual a sua idade?

- 34 Anos

\section{Qual seu cargo na empresa?}

- Sou filho do dono da RLM e cuido das operações e relações comerciais da empresa

\section{Há quanto tempo você presta serviços para a Puig Brasil?}

- Cerca de 2 anos prestamos serviços para a Puig, e hoje ela representa parte significativa do faturamento da RLM.

5. Você considera seus serviços para a Puig Brasil como: Importante, relativamente importante ou facilmente substituível? Por que?

- Considero como importante, pois com o nível de detalhe que atendemos eles e com o timming que eles precisam não acho que isso é encontrado facilmente dentro do mercado aqui no Rio de Janeiro.

\section{O fluxo de informação dentro do processo é claro para você?}

- Não, por muitas vezes tenho duvidas sobre algum ponto, e quando vou procurar saber junto a Puig tenho, por muitas vezes, dificuldade na obtenção das respostas por procurar pessoas erradas ou por não saber a quem procurar.

7. Numa escala de 1 a 5 , sendo 1 muito ruim e 5 ótimo, classifique e explique o nível de eficiência de eficácia do processo.

- Nesse ponto dou nota 2, existem muitos aspectos a serem melhorados dentro do processo. Seja na execução, seja na entrega final. Ao longo do processo temos muitos 
problemas que são difíceis de serem resolvidos por falta de informação de ambas as partes o que acabam gerando atrasos, o que não é bom para nós RLM.

8. Qual seria, na sua opinião, o melhor indicador para avaliar a eficiência e a eficácia do processo?

- Penso que o melhor indicador para ser utilizado seria um que considerasse a opinião de satisfação dos fornecedores da Puig, que são parte fundamental dentro do processo.

\section{Você apontaria alguma mudança para o processo? Por que?}

- Acho que um ponto a ser mudado seria justamente a maneira de como o fluxo de informação é feita. Do jeito que está, nós (fornecedores) temos bastantes problemas na resolução de problemas simples que acabam gerando retrabalho para ambas as partes.

10. Numa escala de 1 a 5 , sendo 1 muito ruim e 5 ótimo, classifique o nível de satisfação do processo e explique o porque desta nota.

- Minha nota é 1, o processo de contas a pagar da organização não atende bem as minhas necessidades. Acontecem erros recorrentes, atrasos, retrabalhos. Mudanças no mesmo são necessárias, fico feliz com a realização deste trabalho. Penso que ele será muito valioso para a empresa como um todo. 